\title{
Comparison of five integrative samplers in laboratory for the monitoring of indicator and dioxin-like polychlorinated biphenyls in water
}

\author{
Romain Jacquet $^{\mathrm{a}}$, Cécile Miège ${ }^{\mathrm{a}, *}$, Foppe Smedes ${ }^{\mathrm{b}, \mathrm{c}}$, Céline Tixier ${ }^{\mathrm{d}}$, Jacek Tronczynski ${ }^{\mathrm{d}}$, \\ Anne Togola ${ }^{\mathrm{e}}$, Catherine Berho ${ }^{\mathrm{e}}$, Ignacio Valor ${ }^{f}$, Julio Llorca $^{f}$, Bruno Barillon $^{\mathrm{g}}$, P. Marchand ${ }^{\mathrm{h}}$, \\ Marina Coquery ${ }^{a}$
}

\author{
${ }^{a}$ Irstea, U.R. MALY, 5 rue de la Doua, CS70077, 69626 Villeurbanne Cedex, France \\ ${ }^{\mathrm{b}}$ Deltares, PO Box 85467, $3508 \mathrm{AL}$, Utrecht, The Netherlands \\ ${ }^{c}$ Masaryk University, RECETOX, Kamenice 126/3, 62500 Brno, Czech Republic \\ d Ifremer, RBE-BE-LBCO, rue de l'lle d'Yeu, 44311 Nantes Cedex 3, France \\ e BRGM, Monitoring and Analysis Division, 3 Avenue Claude Guillemin, 45060 Orléans, France \\ ${ }^{f}$ LABAQUA, c/Dracma 16-18, Poligono Industrial Las Atalayas, 03114 Alicante, Spain \\ ${ }^{g}$ Suez Environnement CIRSEE, 38 rue du Président Wilson, 78230 Le Peck, France \\ h LUNAM University, ONIRIS, LABERCA, Atlanpôle -La Chantrerie, BP 50707, Nantes 44307, France \\ *: Corresponding author : Cécile Miège, tel.: +33 472208744 ; fax: +33 478477875 ; \\ email address : cecile.miege@irstea.fr
}

\begin{abstract}
:
This study aimed at evaluating and comparing five integrative samplers for the monitoring of indicator and dioxin-like polychlorinated biphenyls (PCBs) in water: semi-permeable membrane device (SPMD), silicone rubber, low-density polyethylene (LDPE) strip, Chemcatcher and a continuous-flow integrative sampler (CFIS). These samplers were spiked with performance reference compounds (PRCs) and then simultaneously exposed under constant agitation and temperature in a $200 \mathrm{~L}$ stainless steel tank for periods ranging from one day to three months. A constant $\mathrm{PCB}$ concentration of about $1 \mathrm{ng} \cdot \mathrm{L}^{-1}$ was achieved by immersing a large amount of silicone rubber sheets ("dosing sheets") spiked with the target PCBs. The uptake of PCBs in the five samplers showed overall good repeatability and their accumulation was linear with time. The samplers SPMD, silicone rubber and LDPE strip were the most promising in terms of achieving low limits of quantification. Time-weighted average (TWA) concentrations of PCBs in water were estimated from uptake of PCBs using the sampling rates calculated from the release of PRCs. Except for Chemcatcher, a good agreement was found between the different samplers and TWA concentrations ranged between 0.4 and 2.8 times the nominal water concentration. Finally, the influence of calculation methods (sampler-water partition coefficients, selected PRCs, models) on final TWA concentrations was studied.
\end{abstract}

\section{Highlights}

We compare uptake kinetics for five integrative samplers applied for PCB in water. The method to calculate TWA concentrations strongly influences results. SPMD, SR and LDPE strip are the most efficient to accumulate PCB.

Keywords : Integrative samplers ; Polychlorinated biphenyls ; Water monitoring ; Time weighted average concentration ; Modeling 


\section{Introduction}

Like many other hydrophobic organic contaminants, polychlorinated biphenyls (PCBs) have toxic effects on living organisms, including human beings (Carpenter, 2006). In aquatic environments, PCBs are principally adsorbed on particulate matter due to their hydrophobicity $\left(\log K_{\mathrm{ow}}>4.5\right)$; hence, their concentration in the dissolved phase is therefore very low, typically in the $\mathrm{ng} / \mathrm{L}$ to $\mathrm{pg} / \mathrm{L}$ range. Monitoring such low concentrations with traditional bottle (or grab) sampling is challenging and requires sophisticated analytical methods such as isotopic dilution mass spectrometry. Furthermore, grab sampling only provides a snapshot of the contaminant concentration at a particular time without taking temporal variations into account.

Since two decades, several integrative sampling devices have been developed for the monitoring of organic contaminants in aquatic environments (Greenwood et al. 2009, Söderström et al. 2009, Lohmann et al. 2012). These samplers enable the improvement of limits of quantification (LOQ) by accumulation and concentration of contaminants over long-term exposure. Moreover, when they are used in the integrative phase of uptake (i.e. integrative samplers), time-weighted average (TWA) concentrations over the exposure period can be calculated, leading to a better representativeness of measurements.

Several integrative samplers, at different stages of development, are now available for monitoring non-polar organic contaminants. The semi-permeable membrane device (SPMD) is one of the most comprehensively studied integrative sampler; it consists of a low-density polyethylene (LDPE) lay-flat tubing filled with a small quantity of triolein. It was designed to sequester and concentrate freely dissolved organic contaminants with log Kow ranging from three to eight and has already been extensively used for the monitoring of PCBs in water (Huckins et al. 2006). Next to biphasic sampling devices like SPMD, singlephase integrative samplers, such as LDPE strip and silicone rubber (SR), are gaining interest due to simpler modelling of contaminant transport processes and easier sample 
processing. Numerous studies have shown the suitability of LDPE strips for the monitoring of hydrophobic organic contaminants, such as polyaromatic hydrocarbons (PAHs) or PCBs in various water bodies (Booij et al. 2003, Carls et al. 2004, Adams et al. 2007, Anderson et al. 2008). Silicone rubber was also found to be a suitable alternative to SPMD for the monitoring of hydrophobic contaminants (Rusina 2007). Indeed, SR sheets have been successfully used for the monitoring of PAHs and PCBs from 2002 in The Netherlands (Smedes 2007). Chemcatcher can house different combinations of receiving phases and membranes as appropriate for polar or non-polar contaminants monitoring (Greenwood et al. 2007). The first non-polar version of Chemcatcher, made of a C18 Empore disk and a LDPE membrane, aimed at sampling contaminants with log $K_{0}$ greater than three (Kingston et al. 2000). A recent optimization of the sampler, by adding a small volume of octanol between the receiving phase and the membrane, was proposed to decrease the internal sampler resistance to mass transfer of hydrophobic compounds with log $K_{\text {ow }}$ above five (Vrana et al. 2005). Chemcatcher has already been used during field campaigns for the monitoring of PAH and organochlorine pesticides (Vrana et al. 2010). Finally, developed since 2008, CFIS (Continuous Integrative Flow Sampler) is a new active (i.e. using a pump) sampler designed for the determination of TWA concentrations of organic compounds in water (Llorca et al. 2009). Briefly, CFIS is a fully immersible device consisting of a small peristaltic pump powered by batteries and producing a constant water flow through the glass cell containing a PDMS sorbent. The main advantage of CFIS is that sampling rates are unaffected by water turbulence or velocity and thus, the use of performance reference compounds (PRCs) is not required. It has already been used for the monitoring of $\mathrm{PAH}$ and organochlorine pesticides in wastewater treatment plant effluent (Llorca et al. 2009).

Over the past 20 years, a variety of models has been developed to better describe the transfer kinetics of hydrophobic contaminants into integrative samplers (Booij et al. 
100

101

102

103

104

105

106

107

108

109

110

111

112

113

114

115

116

117

118

119

120

2007). Whatever the integrative sampler and model considered, the calculation of TWA concentrations of contaminants in water from amounts accumulated in the sampler requires the knowledge of sampling rate $\left(R_{S}\right)$ and sampler-water partition coefficient $\left(K_{\mathrm{SW}}\right)$ for each compound. Sampling rates are determined by laboratory calibration under controlled exposure conditions. In situ $R_{s}$ calibration is needed to take into account differences between laboratory vs. in situ exposure conditions (i.e. flow velocity, biofouling or temperature); it is achieved by the use of internal surrogates (performance reference compounds, PRCs), spiked in samplers prior to exposure (Huckins et al. 2002). $K_{\text {Sw }}$ can be determined experimentally (Smedes et al. 2009 for LDPE and SR) or estimated via empirical relationships as a function of log Kow (Huckins et al. 2006 for SPMD, Vrana et al. 2006 for Chemcatcher, Booij et al. 2003, Adams et al. 2007 and Lohmann and Muir 2010 for LDPE). Concerning CFIS, that is an "active" sampler, the use of PRC and $K_{\mathrm{SW}}$ is not necessary. Indeed, a pump enables to control the water flow during exposure and the temperature effect is known by previous calibration in laboratory (from $5^{\circ} \mathrm{C}$ to $3^{\circ} \mathrm{C}$ ). By this way, $R_{s}$ estimated in laboratory for each PCB is corrected according to the average temperature encountered during in situ exposure, to be directly used for the determination of TWA concentrations (Llorca et al. 2009).

Very few intercomparison exercises on integrative samplers have been performed until now. Allan et al. (2009) or Miège et al. (2012) tested in situ the performance of several PSs (including non-polar Chemcatcher, LDPE, membrane enclosed sorptive coating - MESCO, SR and SPMD) for the monitoring of hydrophobic compounds (among PAHs, PCBs or organochlorine pesticides) in the river Meuse (The Netherlands) (Allan et al. 2009) or the river Rhône (France) (Miège et al. 2012) respectively. Although different integrative samplers and methods of calculation were used, relatively consistent TWA concentrations were obtained (variation by a factor up to two). Allan et al. (2010) compared under laboratory conditions the performances of six different integrative 
samplers (non-polar Chemcatcher, SPMD, silicone rod and strip and two modified versions of MESCO), exposed in a flow-through calibration system with Meuse river water spiked with PAHs, PCBs and organochlorine pesticides (concentrations ranging from 20 to 700 $\mathrm{ng} / \mathrm{L})$. This laboratory experiment only lasting five days showed that the mass of contaminant absorbed normalized to the sampler surface area was comparable if uptake was controlled by diffusion through the water boundary layer.

In the context of the ECLIPSE project $(2009-2011)^{1}$, we have studied five integrative samplers that well represent the various types used nowadays for PCBs in term of receiving phase and configuration (dimensions, holders): SPMD, SR, LDPE strip, Chemcatcher (apolar version) and CFIS. After PRC spiking or not, samplers were exposed under constant agitation and temperature in water contaminated with 19 indicator and dioxin-like PCBs for periods ranging from one day to three months. A constant PCB concentration of about $1 \mathrm{ng} / \mathrm{L}$ was achieved by immersing a large amount of spiked silicone rubber sheets (Rusina et al. 2010). Using these five samplers allows comparing different strategies for integrative sampling: passive vs. active (with pump) sampling, use of PRC or not, use of different models and equations to assess TWA concentration. By exposing these five integrative samplers into the same experimental calibration system, a first objective was to compare their performances in accumulating PCBs (uptake, repeatability and linearity). Moreover, since there is no detailed guideline on integrative sampling, a second objective was to compare different methods of calculation of TWA concentrations (models, partition coefficients values and selected PRCs).

\section{Materials and methods}

2.1. Integrative samplers

\footnotetext{
${ }^{1}$ EChantilLonneurs Intégratifs pour la mesure de PCB dans la phase disSoute de miliEux aqueux, 20092011, coord. Irstea (C. Miège), funded by the French Axelera cluster
} 
151 tested and main steps of their processing are summarized in Table 1. Further details on

152 their characteristics, pretreatment and analysis are given in Supplementary data (S1).

\subsection{Target molecules}

The exposure of samplers was performed with 19 PCBs: PCB 18, indicator PCBs (PCB 28, 52, 101, 118, 138, 153 and 180) and dioxin-like PCBs (PCB 77, 81, 105, 114, 118, 123, 126, 156, 157, 167, 169 and 189). All these PCBs were purchased from Cil Cluzeau (Courbevoie, France) and delivered in a custom-made solution used to spike the silicone rubber sheets (referred as "dosing sheets" hereafter).

\subsection{Exposure device and strategy}

The exposure device was custom-made (PIC, Olivet, France) and consisted of a tank (height $=120 \mathrm{~cm}$, diameter $=47 \mathrm{~cm}$ ), a stirrer and six holders; all these pieces being made of stainless steel to minimize adsorption. A scheme of the exposure device is presented in Supplementary data (S2). The tank was filled with $200 \mathrm{~L}$ of tap water agitated with a stirrer (height $=100 \mathrm{~cm}$, width $=18 \mathrm{~cm}$ ) set in motion by an electronic engine

167 (Heidolph RZR 2102 control Z; VWR, Fontenay-sous-Bois, France). Rotation speed was set at $33 \mathrm{rpm}$ to obtain a water velocity of about $5 \mathrm{~cm} / \mathrm{sec}$ near the samplers exposed in the tank. To regulate water temperature, the exposure tank was placed in a $300 \mathrm{~L}$

170 polyethylene tank (CVC series, Manutan, Gonesse, France) and water was cooled by an 171 aquarium chiller (Teco TR20, Europrix, Lens, France). The exposure tank contained six 172 holders (height $=100 \mathrm{~cm}$, width $=20 \mathrm{~cm}$ ) set along the wall. Two holders were used to 173 support the dosing sheets and the four other holders were used to fix four types of 174 integrative samplers: SPMD, SR, LDPE strip and Chemcatcher. Each holder had four 
175 positions enabling the simultaneous exposure of four samplers at different depths. CFIS 176 were installed outside the tank but were exposed to the tank water by use of glass tubes. PCBs were dosed to the tank water by immersing a large amount of dosing sheets 178 (Rusina et al. 2010). This allowed for maintaining a constant concentration of about $1 \mathrm{ng} / \mathrm{L}$ 179 of each studied PCB throughout the experiment. Dosing sheets were first mounted in the 180 exposure device and the tank was filled with tap water. Then, the exposure system was 181 allowed to equilibrate under agitation and temperature regulation during two days, after 182 which water was renewed. This step allowed for cleaning the system and eliminating 183 traces of methanol that might have remained in the dosing sheets from spiking. After 184 another two days of equilibration, samplers were deployed in the tank.

Exposures in the water tank lasted up to three months. SPMD, SR and LDPE strips 186 were exposed during 1, 3, 7, 14, 21, 28 (in triplicate), 56 and 91 days. Chemcatcher and 187 CFIS were exposed during 3, 7, 14 (in triplicate), 21, 28 and 56 days. Before and after 188 exposure, samplers were stored at $-20^{\circ} \mathrm{C}$.

Temperature of the tank water was recorded every $6 \mathrm{~h}$ over the whole exposure duration. During the first month, water $(1 \mathrm{~L})$ was sampled weekly for determination of $\mathrm{pH}$, 191 conductivity and dissolved organic carbon (DOC) concentration. During the last two 192 months, these measurements were performed every two weeks. The concentrations of PCBs in water were calculated from their concentration in dosing sheets (Rusina et al., 194 2010) and using their PDMS - water partition coefficients (Smedes et al. 2009). Dosing sheets were sampled every two weeks by cutting six small pieces at different depths in the 196 tank obtaining a total amount of about $1 \mathrm{~g}$ of material. Further details about the preparation 197 and analysis of dosing sheets are given in Supplementary data (S1). 
In order to assess the interlaboratory variability in PCB analysis, a standard solution

was prepared and sent for analysis by each of the five laboratories involved in this study with its own analytical method. This solution contained the 19 studied PCBs at concentrations ranging from 50 to $130 \mu \mathrm{g} / \mathrm{L}$ and was conditioned in amber glass vials prior to shipment. A good agreement was found between laboratories since the relative standard deviations (RSD) on measured concentrations ranged from 3 to $13 \%$ depending on the congeners.

\subsubsection{Blank samplers}

After their preparation, several samplers were kept as procedural blanks in order to evaluate any possible contamination during fabrication, spiking, storage, processing and analysis. These procedural blanks were stored at $-20^{\circ} \mathrm{C}$ until processing. Other samplers were used as "field" blanks and exposed to the ambient air during the handling of deployed samplers to take account for any possible contamination during deployment and retrieval. These "field" blanks were stored at $-20^{\circ} \mathrm{C}$ until pro cessing. No contamination by PCB was measured in procedural and field blanks.

At last, for each type of sampler (except CFIS), a blank sampler (not spiked with PRC) was exposed in the tank during the whole exposure duration in order to assess any possible contamination with PRC between samplers. Only low amounts of rapidly releasing PRC were observed representing less than $4 \%$ of the concentration in these exposed spiked samplers.

\subsection{Calculations}

Several models have been developed to describe the transfer of hydrophobic contaminants into the various available integrative samplers and to calculate the TWA concentrations in water from the accumulated amounts in the samplers (Booij et al. 2007). 
PCBs in water were calculated from the following equation (Huckins et al. 2006):

$$
C_{W}=\frac{N}{V_{S} K_{S W}\left(1-\exp \left(-\frac{R_{S} t}{V_{S} K_{S W}}\right)\right)}
$$

230 where $C_{W}$ is the TWA concentration of PCB in water (ng/L), $N$ is the mass of PCB

231 accumulated in sampler $(\mathrm{ng}), V_{S}$ is the volume of sampler $(\mathrm{L}), K_{S W}$ is the sampler-water 232 partition coefficient of PCB (L/L), $R_{S}$ is the sampling rate of PCB (L/day) and $t$ is the 233 exposure duration (day). For SR and LDPE, $V_{S}$ is replaced by $M_{S}$, the mass of sampler $234(\mathrm{~kg})$, and $K_{\mathrm{SW}}$ is expressed in $\mathrm{L} / \mathrm{kg}$.

For CFIS, TWA concentrations of PCBs were calculated from the following equation, which is a simplification of equation 1 for the sampling during the linear uptake phase (Huckins et al. 2006):

$238 \quad C_{W}=\frac{N}{R_{S} t}$

More details on calculations of TWA concentrations of PCBs in water for each sampler are given in Table 2 and Supplementary data (S3).

\section{Results and discussion}

\subsection{Exposure conditions}

During the three months exposure, water temperature remained constant $\left(22.6^{\circ} \mathrm{C} \pm\right.$

$\left.0.1^{\circ} \mathrm{C}\right)$ and $\mathrm{pH}$ only slightly varied $(7.5 \pm 0.2)$. In contrast, water conductivity slightly decreased from 380 to $310 \mu \mathrm{S} / \mathrm{cm}$ and DOC concentration showed an increase from 247 around 1.5 to $5 \mathrm{mg} / \mathrm{L}$ (Supplementary data, S4). These variations of conductivity and DOC could be explained by the development of biofouling in the tank since no biocide was added. Another possible source of DOC could be the release of the octanol used in the 
251 between 3 and $11 \%, n=7$ ) and derived water concentrations ranged from $0.37 \mathrm{ng} / \mathrm{L}$ (PCB 252 189) to $3.80 \mathrm{ng} / \mathrm{L}$ (PCB 114), with a mean value of $1.29 \mathrm{ng} / \mathrm{L}$. The exposure conditions were therefore considered as constant during the whole experiment.

\subsection{Comparison of uptake curves and PRC candidates}

To compare the uptake of the five studied integrative samplers, this uptake was normalized to a surface area of $100 \mathrm{~cm}^{2}\left(N_{\mathrm{A}}\right)$. Plotting $N_{\mathrm{A}}$ versus time showed that the uptake rate (slope) ranged within a factor five as depicted in Figure 1A for PCB 81 (4 Cl atoms), PCB 114 (5 Cl atoms), PCB 138 (6 Cl atoms) and PCB 180 (7 Cl atoms). With were quite similar, whereas SR was showing considerable higher uptake than SPMD. This could have been caused by the fact that SPMD and LDPE were both similarly fixed on a spider holder perpendicular to the flow, whereas SR was fixed in parallel with the flow (S2). The overall lower $N_{\mathrm{A}}$ for Chemcatcher is likely connected to the "beaker" shape configuration creating a longer diffusion path between sampler and bulk water. For CFIS, the $N_{\mathrm{A}}$ was not expected to be comparable as this sampler has its own flow regime; but by chance, this $N_{\mathrm{A}}$ was at the same level as that of the passive samplers. Remarkable is that 268 CFIS showed the highest $N_{A}$ (PCB 138 and 180) as well as the lowest (PCBs 81 and 114). It seems that for CFIS, the $N_{\mathrm{A}}$ for indicator PCBs were markedly higher than for dioxin-like PCBs, a phenomenon that was not observed for the other samplers.

Although, the $N_{\mathrm{A}}$ of most PCBs were linear with time for the whole exposure duration; there were some outliers, indicated by (a) in Figure 1. Indeed, the $N_{\mathrm{A}}$ for SPMD 273 exposed for 91 days was similar to that at 56 days, and that even occurred for the most 274 hydrophobic PCBs that could impossibly have obtained equilibrium. The low $N_{\mathrm{A}}$ of the SPMD at 91 days exposure however coincides with a reduced release of PRCs, as shown 276 in Figure 1B for PCB 29. It is not clear whether the lower exchange for the SPMD 
exposed during 91 days is caused by observed biofouling or different mounting position of the spider holder giving a different flow regime. Anyway, these observations underline the importance of PRC application. Figure 1B shows the release curves of some PRC candidates spiked in samplers prior to exposure. PRCs were selected according to the criteria reported in Table 2. The release rates of PRCs were used to calculate the TWA concentrations of PCBs in section 3.4.1.

For LDPE strip, PCBs 18, 28 and 52 reached the equilibrium phase of uptake within the 91 days of exposure and PCBs 77, 81 and 101 were in the curvilinear uptake phase, as was PCB 18 in SPMD. With the exception of these less hydrophobic congeners, $N_{\mathrm{A}}$ in LDPE strip, as well as in SR, Chemcatcher and CFIS, increased during the three months of exposure with an overall good linearity. Linear uptake phase durations of all PCBs are given in Supplementary data for SPMD, SR and LDPE strip (S5).

\subsection{Discussion on sampling rates}

When $N_{\mathrm{A}}$ is divided by $\left(t \times C_{\mathrm{W}}\right)$, a $R_{\mathrm{SA}}\left(\mathrm{L} . \mathrm{d}^{-1} .100 \mathrm{~cm}^{-2}\right)$ is obtained for the compounds in linear kinetic phase (cf. equation 2). Figure 2 allows comparing the $R_{\mathrm{SA}}$ of the different compounds and between the five samplers. It is important to note that $R_{\mathrm{SA}}$ for SPMD, SR and LDPE are close with an average RSD of $21 \%$ whereas that value increases to $43 \%$ when data of all samplers are considered. PCBs approaching equilibrium (grey bars) were not included.

Figure 2 is based on the 28 days exposures for SPMD, SR and LDPE, and on the 14 days exposures for Chemcatcher and CFIS, because these exposures were performed in triplicate and allowed an evaluation of the uptake repeatability (error bars in Figure 2). Overall, repeatability of $R_{S A}$ was very satisfying, with a mean value of $R S D$ (combining all the 19 PCBs) lower than $14 \%$ (9\% for SPMD, $5 \%$ for SR, $7 \%$ for LDPE, $9 \%$ for 
302 Chemcatcher and $14 \%$ for CFIS). This variability was only slightly higher than that 303 observed in the dosing sheets over time.

304 Despite the differences in materials (membranes, sequestering phases) and 305 configurations, SPMD, SR, LDPE strip and Chemcatcher exhibited similar patterns of $R_{\mathrm{SA}}$ 306 contrary to CFIS. Ignoring the compounds that were approaching equilibrium (PCB 18, 307 PCB 28 and PCB 52), the RSD of the $R_{\mathrm{SA}}$ ratios between two samplers (1 ratio per PCB, $308 \mathrm{n}=16$ to 19) can be used as a measurement for agreement between patterns. This 309 revealed that the pattern ratio between SPMD and SR showed a RSD of $10 \%$ (average 310 ratio of 0.7 ) and excellent agreement. For both SPMD-LDPE and SR-LDPE, the RSD of 311 the pattern ratio was $16 \%$, with average ratios of 0.9 and 1.2 respectively. This larger 312 RSD for LDPE was due to relatively higher uptakes of PCBs 77, 81, 126 and 169, i.e. of 313 non-ortho substituted PCBs. For SPMD-Chemcatcher and SPMD-CFIS, the pattern 314 agreement was much lower with RSD of $40 \%$ and $50 \%$ and average ratios of 2.1 and 1.2 , 315 respectively. For SPMD-Chemcatcher, leaving PCB 189 out reduced the RSD of the 316 pattern ratio to $23 \%$. The different level of $R_{S A}$ for the CFIS sampler can be explained by 317 the different flow regime in the cell (outside the tank) compared to that inside the tank, but 318 we cannot explain the much higher $R_{\mathrm{SA}}$ of the indicator PCBs compared to those of the 319 dioxin-like PCBs. The RSD of pattern ratios for the membrane samplers were consistent 320 and only about a factor two higher than the repeatability of $\mathrm{R}_{\mathrm{SA}}$ for each triplicate samplers; 321 this indicates that uptake processes of the different compounds were similar for SPMD, SR 322 and LDPE.

Between compounds, $R_{\mathrm{SA}}$ values were quite scattered (20 to $50 \% \mathrm{RSD}$ ). To 324 explain this scatter between compounds, the origin of $C_{W}$ should be considered. The calculation of $R_{S A}$ in the evaluation above was actually done according to: 
$R_{S A}=\frac{N_{A}}{t C_{W}}=\frac{N_{A} K_{S W}}{t C_{\text {Dose }}}$

329 where $C_{\text {Dose }}$ is the concentration in the sheets dosing the water phase. Equation 3 clearly

330 shows that $R_{\mathrm{SA}}$ is proportional to $K_{\mathrm{SW}}$ and any uncertainty in the $K_{\mathrm{SW}}$ is included in $C_{\mathrm{W}}$ and,

331 subsequently in the value of $R_{\mathrm{SA}}$. The $K_{\mathrm{SW}}$ has a considerable uncertainty (Difilippo and

332 Eganhouse 2010) and can easily be in the same range as the between compound 333 variation of 32,31 and $41 \%$ observed for SPMD, SR and LDPE respectively. The $K_{\text {SW }}$ 334 uncertainty can also explain why the expected decrease of $R_{\mathrm{SA}}$ with increasing 335 hydrophobicity (and Mw) (Booij et al. 2003, Huckins et al. 2006 Rusina et al. 2010) is not 336 visible.

\subsection{Evaluation of TWA concentrations}

3.4.1. Comparison of TWA concentrations

340 The TWA concentrations of PCBs in water were calculated from PCB uptake and PRC 341 release (except for CFIS) measured for triplicate samplers exposed during 14 days for 342 Chemcatcher and CFIS and during 28 days for SPMD, SR and LDPE strip. The 343 calculations of TWA concentrations were first carried out as indicated by the developer of 344 the sampling system as listed in Table 2 and Supplementary data (S3). For Chemcatcher, 345 the model used for calculations was stated to be only applicable for compounds with $346 \log K_{0 w}$ ranging from 3.7 to 6.8 (Vrana et al. 2007) but was applied also for more 347 hydrophobic PCBs. For SPMD, LDPE strip and Chemcatcher, TWA concentrations of 348 PCBs in water were calculated using only PRCs whose dissipation was between 20 and $34980 \%$ in order to prevent quantification problems due to insignificant release or 350 concentrations close to LOQ. In contrast, all PRCs spiked in SR were used (Booij and 351 Smedes, 2010). PRC-based sampling rates for SPMD, SR and LDPE strip are given in 352 Supplementary data (S6). Required $\log K_{\mathrm{Sw}}$ for SR and LDPE strip were available in the 
353 literature, mostly experimentally determined and modeled for six of the dioxin-like PCBs 354 (Smedes et al. 2009). For SPMD and Chemcatcher, $\log K_{\mathrm{SW}}$ were determined from 355 empirical relationships as a function of log Kow (Huckins et al. 2006, Vrana et al. 2006). For 356 CFIS, with no PRC used, TWA concentrations of indicator PCBs were computed with $R_{S}$ 357 previously determined in laboratory calibration experiments (Llorca et al. 2009). Sampling 358 rates of dioxin-like PCBs were extrapolated from $R_{S}$ of indicator PCBs having the same 359 number of chlorine atoms.

360 For Chemcatcher, repeatability between triplicate samplers was satisfying (12-22 $361 \%)$ but TWA concentrations of PCBs in water were up to 12 times higher than the average 362 of the four other samplers, suggesting that the use of the model (Vrana et al. 2006, 2007) 363 for hydrophobic compounds was not applicable for PCBs. Chemcatcher results were 364 therefore not included in the comparison between samplers.

365 Figure 3 shows the ratios of the TWA concentrations of PCBs calculated from the 366 four samplers and the nominal concentrations of PCBs in water derived from 367 concentrations in dosing sheets. Overall, concentrations computed from the four samplers 368 were reasonably close. The highest difference was observed for PCB 153 with a factor of 369 eight between the lowest calculated concentration ( $0.5 \mathrm{ng} / \mathrm{L}$ for LDPE strip) and the 370 highest (4.0 ng/L for CFIS). For SPMD, calculated TWA concentrations of the 19 PCBs 371 were between 0.8 and 2.1 times (average 1.5) the nominal concentrations in water. 372 Repeatability between triplicate samplers was between 8 and $26 \%$ (average $15 \%$ ). The 373 same tendency was observed for SR, with calculated TWA concentrations between 1.5 374 and 2.8 times (average of 2.1) higher than the nominal concentrations in water, and with 375 RSD for triplicate samplers between 10 and $27 \%$ (average $18 \%$ ). In contrast, for LDPE 376 strip, TWA concentrations were found between 0.4 and 1.2 times (average of 0.7 ) the 377 nominal concentrations in water with RSD between 7 and $22 \%$ (average $13 \%$ ). Finally, 378 for CFIS, TWA concentrations were between 0.5 and 5.0 times (average 1.5) the nominal 
379

380 381 illustrated in Figure 3. strips methods.

concentrations in water and RSD between 2 and $80 \%$ (average $21 \%$ ). For CFIS, PCBs 180 and 153 were mainly responsible for high mean RSD and TWA concentration, as

In summary, except for Chemcatcher, TWA concentrations of PCBs computed from the different samplers were in agreement with concentrations in water calculated from dosing sheets and good repeatability was found. These results are very satisfying considering that they were obtained from different samplers, processed in different laboratories and obtained with different calculations methods (i.e. different models, different selection criteria of PRCs and $\log K_{\text {sw }}$ either experimentally determined or extrapolated from empirical relationship function of $\left.\log K_{\mathrm{ow}}\right)$.

3.4.2. Influence of the data treatment method (PRC and $K_{S W}$ ) for SPMD, SR and LDPE

The method of calculation (the model used, the selection and the use of PRCs, the choice of the partition coefficients) influences the TWA concentration results for a given sampler. In order to observe the influence of these parameters, TWA concentrations for the 28 days exposures were calculated again for SPMD, SR and LDPE with alternative

For SPMD, initial log $K_{\text {sw }}$ used in part 3.4.1., obtained from the empirical model of Huckins et al. (2006), was replaced by new log $K_{\text {sw }}$ according to Booij and Smedes (2011). For SPMD and LDPE, we also tested to use all the PRCs spiked (see Table 1), following the method of Booij and Smedes (2010). At the opposite, for SR, instead of using all the PRCs, we considered only PRCs whose release after 28 days were between 20 and $80 \%$; three PRCs (i.e. PCBs 2, 3 and 10) were then retained. TWA concentration from SR were then calculated with PCBs 2, 3 and 10 and were found similar (RSD $<7 \%$ ), we only present results obtained with PCB 10 because of a smaller RSD. 
The ratios of the TWA concentrations on the concentrations of PCBs in water

406 calculated from dosing sheets are illustrated in Figure 4. For SPMD, in spite of using a 407 different relation for $\log K_{\mathrm{sw}}$, the differences on TWA concentrations were relatively small 408 (slight decrease with Ksw from Booij and Smedes, 2011). Indeed, the relation mainly 409 affects the more hydrophobic PCBs but not the PRCs (low hydrophobic PCBs). 410 Consequently, the sampling rate used to calculate $C_{\mathrm{w}}$ for the more hydrophobic PCBs is 411 slightly affected. Besides, the use of all the PRCs spiked in SPMD, instead of only one, 412 resulted in a very slight increase of TWA concentrations. For SR, the change in PRC used 413 induced a slight decrease of the TWA concentrations. Indeed, by using only one PRC, 414 these concentrations were between 1.1 and 2.1 times higher than the concentrations in 415 water (with an average of 1.6), instead of 2.1 found with all PRCs. For LDPE, the use of all 416 PRCs instead of only one resulted in slight increase of TWA concentrations.

Note that the variations in PRC choice above are for illustration. We recommend 418 using all PRCs for $R_{\mathrm{S}}$ estimation as no information is lost and uncertainties in log $K_{\mathrm{sw}}$ of the 419 PRC may be averaged out. However uncertainty in $\log K_{\text {sw }}$ remains an issue also for target 420 compounds. Measurement of accurate log $K_{\text {sw }}$ is very difficult, experimental log $K_{\text {sw }}$ values 421 are scarce and can be considerably scattered (Difilippo and Eganhouse, 2010). Models 422 predicting the $\log K_{\text {sw }}$ from log $K_{\text {ow }}$ can have typical uncertainties ranging from $0.13-0.36$ $423 \log$ unit (factor 1.4-2.4) (Booij and Smedes 2010). Moreover, the selection of other log $K_{\mathrm{OW}}$ sources than those used for creating the predictive relations, may contribute to further variability. Considering the above, the results reported here for the three membrane samplers with a general variation of about a factor two are very satisfying, as they were 427 based on $\log K_{\text {sw }}$ either experimentally determined or from an empirical relationship with 428 log $K_{\mathrm{OW}}$, different calculations models, different selection criteria of PRCs, and obtained from different samplers, processed in different laboratories. 


\section{Conclusions}

The designed calibration system for the simultaneous exposure of the five

433 integrative samplers enabled to maintain sufficiently constant exposure conditions up to

434 three months and PCB uptake in samplers showed overall good linearity with time and 435 repeatability. The three membrane samplers (SR, LDPE and SPMD) are efficient to 436 accumulate large amounts of PCBs and have great potential for low LOQ when used in 437 water monitoring programs. TWA concentrations of PCBs in water calculated from the 438 different samplers were in good agreement, except for Chemcatcher whose model for 439 hydrophobic compounds (Vrana et al., 2006, 2007) was not proven to be suitable for PCBs 440 in this study. For the four other samplers, despite the variety of materials, geometries and 441 calculation methods, TWA concentrations were generally between 0.5 and 3 times the 442 nominal water concentrations calculated from dosing sheets, which is quite satisfying in 443 the domain of ultra-trace (ng/L level) micropollutants analysis in aquatic environments.

At last, it must be underlined that TWA concentrations in water can be calculated through the use of various models, PRCs and $\log K_{\mathrm{sw}}$ values. For the transfer of these sampling tools to water basin managers, it is therefore of crucial importance that protocols 447 detail the calculation methods. Moreover, any results on TWA concentration (from the 448 literature or in situ monitoring programs) should be accompanied with detailed information 449 on calculation method used (i.e. model and equations, PRCs and $\log K_{\text {sw }}$ values). Intercomparison exercises on sampling and processing, but also the determination

451 of partition coefficients $\mathrm{K}_{\mathrm{sw}}$, should enable to progress on the knowledge and 452 harmonization of practices for the use of integrative sampling, especially for priority 453 chemical monitoring and regulatory programs in compliance with the Water Framework 454 Directive and the Marine Strategy Framework Directive. To be noted that the challenge of 455 PRC strategy is even more crucial for integrative samplers used for hydrophilic 456 compounds (i.e. POCIS, polar Chemcatcher, ...), since very few PRC candidates have 
457

458

459

460

461

462

463

464

465

466

467

468

469

470

471

472

473

474

475

476

477

478

479

480

481

482

been found up to date. Further outputs of the ECLIPSE project should follow dealing on the application and comparison of these five integrative samplers in situ.

\section{Acknowledgments}

The ECLIPSE project is part of the French PCB Axelera project, supported by the "Chemistry and environment French competitive" cluster from Lyon and Rhône-Alpes (http://www.axelera.org/en/). We thank Nadège Bely (IFREMER) and Henry Beeltje (TNO - Organisation for Applied Scientific Research, The Netherlands) for technical assistance. The authors thank an unknown reviewer for his constructive comments which helped us to significantly improve the quality of this paper.

\section{Supplementary data}

Supplementary data associated with this article can be found in the online version.

\section{References}

Adams, R.G., Lohmann, R., Fernandez, L.A., Macfarlane, J.K., Gschwend, P.M., 2007. Polyethylene devices: passive samplers for measuring dissolved hydrophobic organic compounds in aquatic environments. Environ. Sci. Technol. 41, 1317-1323.

Allan, I.J., Booij, K., Paschke, A., Vrana, B., Mills, G.A., Greenwood, R., 2009. Field performance of seven passive sampling devices for monitoring of hydrophobic substances. Environ. Sci. Technol. 43, 5383-5390.

Allan, I.J., Booij, K., Paschke, A., Vrana, B., Mills, G.A., Greenwood, R., 2010. Short-term exposure testing of six different passive samplers for the monitoring of hydrophobic contaminants in water. J. Environ. Monit. 12, 696-703. 
484 Anderson, K.A., Sethajintanin, D., Sower, G., Quarles, L., 2008. Field trial and modeling of 485 uptake rates of in situ lipid-free polyethylene membrane passive sampler. Environ. Sci. 486 Technol. 42, 4486-4493.

Booij, K., Hofmans, H.E., Fischer, C.V., van Weerlee, E.M., 2003. Temperature dependent uptake rates of non-polar organic compounds by semi-permeable membrane devices and low-density polyethylene membranes. Environ. Sci. Technol. 37, 361-366.

Booij, K., Vrana, B., Huckins, J.N., 2007. Theory, modeling and calibration of passive samplers used in water monitoring, in: Greenwood, R., Mills, G., Vrana, B. (Eds), Passive sampling techniques in environmental monitoring, Elsevier, Amsterdam, pp. 141-169.

Booij, K, Smedes, F, 2010. An Improved Method for Estimating in Situ Sampling Rates of

Booij, K, Smedes, F, 2011. Correction to An Improved Method for Estimating in Situ

Sampling Rates of Nonpolar Passive Samplers. Environ. Sci. Technol. 45, 10288-10288

501 Carls, M.G., Holland, L.G., Short, J.W., Heintz, R.A., Rice, S.D., 2004. Monitoring polynuclear aromatic hydrocarbons in aqueous environments with passive low-density polyethylene membrane devices. Environ. Toxicol. Chem. 23, 1416-1424.

Carpenter, D.O., 2006. Polychlorinated biphenyls (PCBs): Routes of exposure and effects on human health. Rev. Environ. Health 21, 1-23.

Difilippo, E.L., Eganhouse, R.P., 2010. Assessment of PDMS-water partition coefficients: 509 Implications for passive environmental sampling of hydrophobic organic compounds. 510 Environ. Sci. Technol. 44, 6917-6925. 
512 Greenwood, R., Mills, G.A., Vrana, B., Allan, I.J., Aguilar-Martinez, R., Morrison, G., 2007.

513 Monitoring of priority pollutants in water using Chemcatcher passive sampling devices, in:

514 Greenwood, R., Mills, G., Vrana, B. (Eds), Passive sampling techniques in environmental 515 monitoring, Elsevier, Amsterdam, pp. 199-229.

517 Greenwood R., Mills G.A., Vrana B., 2009. Potential applications of passive sampling for 518 monitoring non-polar industrial pollutants in the aqueous environment in support of 519 REACH. J. Chrom. A, 1216, 631-639.

521 Huckins, J.N., Petty, J.D., Lebo, J.A., Fernanda, V.A., Booij, K., Alvarez, D.A., Cranor, 522 W.L., Clark, R.C., Mogensen, B.B., 2002. Development of the permeability/performance 523 reference compound approach for in situ calibration of semi-permeable membrane 524 devices. Environ. Sci. Technol. 36, 85-91.

526 Huckins, J.N., Petty, J.D., Booij, K., 2006. Monitors of organic chemicals in the 527 environment. Springer, New-York.

530 Kingston, J.K., Greenwood, R., Mills, G.A., Morrison, G.M., Persson, B.L., 2000. 531 Development of a novel passive sampling system for the time-averaged measurement of a 532 range of organic pollutants in aquatic environments. J. Environ. Monit. 2, 487-495.

534 Lohmann, R., Booij, K., Smedes, F., Vrana, B., 2012. Use of passive sampling devices for 535 monitoring and compliance checking of POP concentrations in water: Environ. Sci. Pollut. 536 Res. 19, 1885-1895. 
538 Lohmann, R., Muir, D., 2010. Global Aquatic Passive Sampling (AQUAGAPS): using 539 passive samplers to monitor POPs in the waters of the world. Environ. Sci. Technol. 44, $540860-864$.

542 Llorca, J., Gutiérrez, C., Capilla, E., Tortajada, R., Sanjuán, L., Fuentes, A., Valor, I., 2009. 543 Constantly stirred sorbent and continuous flow integrative sampler. New integrative 544 samplers for the time weighted average water monitoring. J. Chromatogr. A 1216, 57835455792.

Miège, C., Mazzella, N., Schiavone, S., Dabrin, A., Berho, C., Ghestem, J.-P., Gonzalez, C., Gonzalez, J.-L., Lalere, B., Lardy-Fontan, S., Lepot, B., Munaron, D., Tixier, C., Togola, A., Coquery M. 2012. An in situ intercomparison exercise on passive samplers for monitoring metals, polycyclic aromatic hydrocarbons and pesticides in surface waters.

551 Trends in Analytical Chemistry, 36, 128-143.

Rusina, T.P., Smedes, F., Klanova, J., Booij, K., Holoubek, I., 2007. Polymer selection for passive sampling: a comparison of critical properties. Chemosphere 68, 1344-1351.

Rusina, T.P., Smedes, F., Koblizkova, M., Klanova, J., 2010. Calibration of silicone rubber passive samplers: experimental and modeled relations between sampling rate and compound properties. Environ. Sci. Technol. 44, 362-367.

560 Smedes, F., 2007. Monitoring of chlorinated biphenyls and polycyclic aromatic 561 hydrocarbons by passive sampling in concert with deployed mussels, in: Greenwood, R., 562 Mills, G., Vrana, B. (Eds), Passive sampling techniques in environmental monitoring. 563 Elsevier, Amsterdam, pp. 407-448. 
565 Smedes, F., Geertsma, R.W., Van der Zande, T., Booij, K., 2009. Polymer-water partition 566 coefficients of hydrophobic compounds for passive sampling: application of cosolvent 567 models for validation. Environ. Sci. Technol. 43, 7047-7054.

569 Söderström, H., Lindberg R.H., Fick J., 2009. Strategies for monitoring the emerging polar 570 organic contaminants in water with emphasis on integrative passive sampling. J. Chrom. 571 A, 1216, 623-630.

573 Vrana, B., Mills, G.A., Greenwood, R., Knutsson, J., Svenssone, K., Morrison, G., 2005. 574 Performance optimisation of a passive sampler for monitoring hydrophobic organic 575 pollutants in water. J. Environ. Monit. 7, 612-620.

Vrana, B., Mills, G.A., Dominiak, E., Greenwood, R., 2006. Calibration of the Chemcatcher passive sampler for the monitoring of priority organic pollutants in water. Environ. Pollut. 142, 333-343.

Vrana, B., Mills, G.A., Kotterman, M., Leonards, P., Booij, K., Greenwood, R., 2007. Modelling and field application of the Chemcatcher passive sampler calibration data for the monitoring of hydrophobic organic pollutants in water. Environ. Pollut. 145, 895-904.

Vrana, B., Mills, G.A., Leonards, P.E.G., Kotterman, M., Weideborg, M., Hajslova, J., 586 Kocourek, V., Tomaniova, M., Pulkrabova, J., Suchanova, M., Hajkova, K., Herve, S., 587 Ahkola, H., Greenwood, R., 2010. Field performance of the Chemcatcher passive sampler 588 for monitoring hydrophobic organic pollutants in surface water. J. Environ. Monit. 12, 863872. 


\section{Figures}

592 Fig. 1. Surface area normalized uptake $\left(N_{\mathrm{A}}\right)$ plotted versus time (panel A) for PCB $81(4 \mathrm{Cl}$

593 atoms), PCB 114 (5 Cl atoms), PCB 138 (6 Cl atoms) and PCB 180 (7 Cl atoms) in the five

594 integrative samplers. Uptake was normalized to a membrane surface area of $100 \mathrm{~cm}^{2}$.

595 Panel B shows release curves of some selected PRCs.

596 (a) data not used for curve fitting

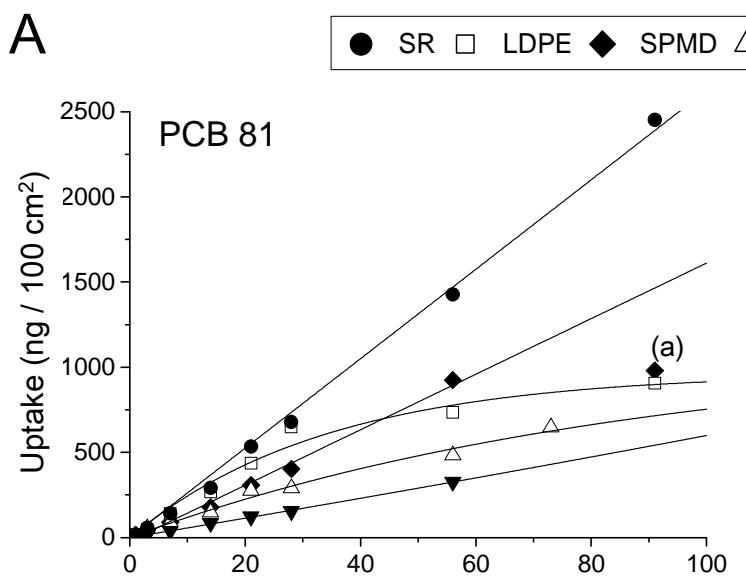

Chemcatcher $\boldsymbol{\nabla}$ CFIS
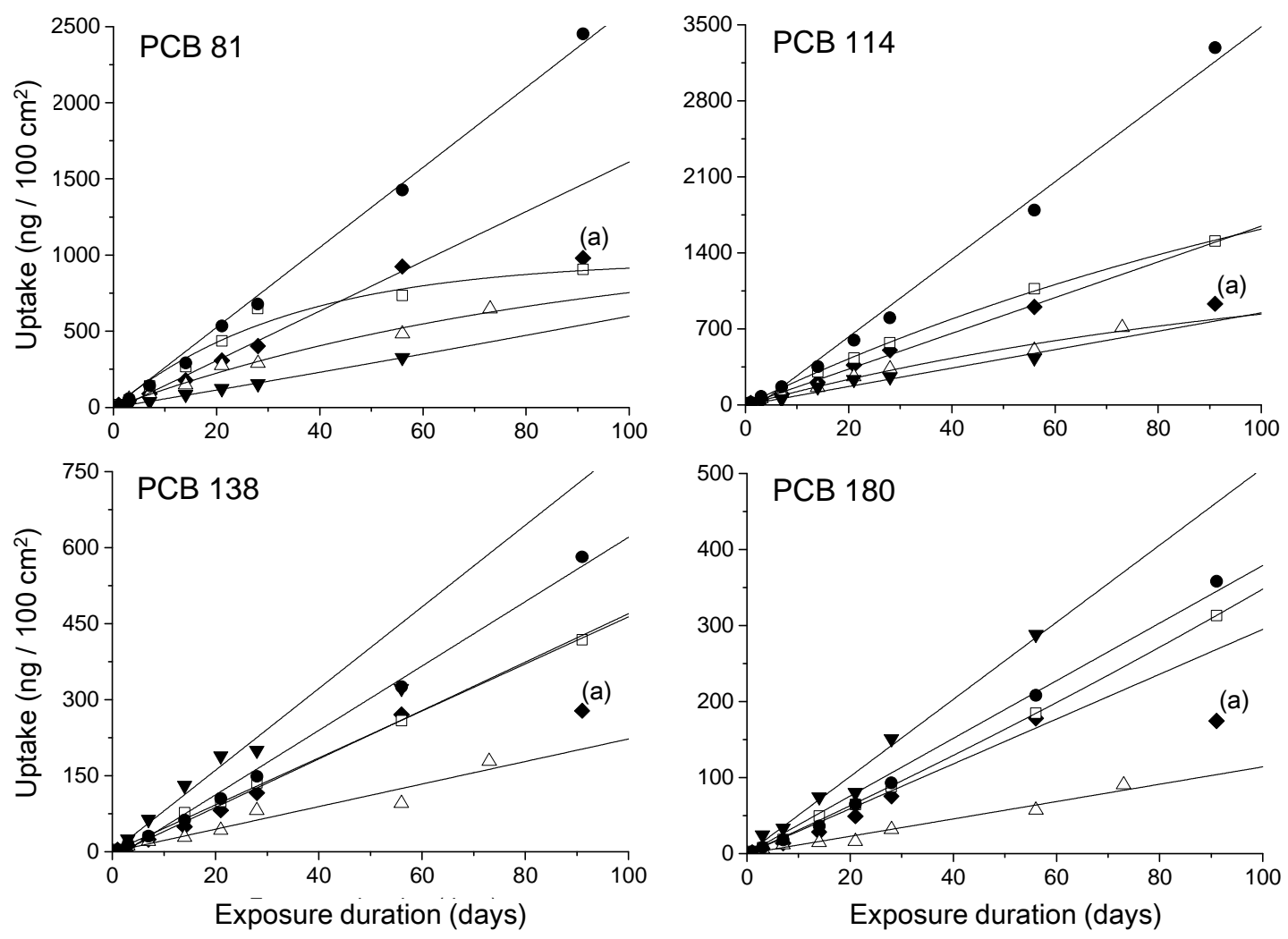

B

- PCB $10(\mathrm{SR}) \square$ PCB $104($ LDPE) $\diamond$ PCB 29 (SPMD) $\triangle$ Fluorene-d10 (Chemcatcher)

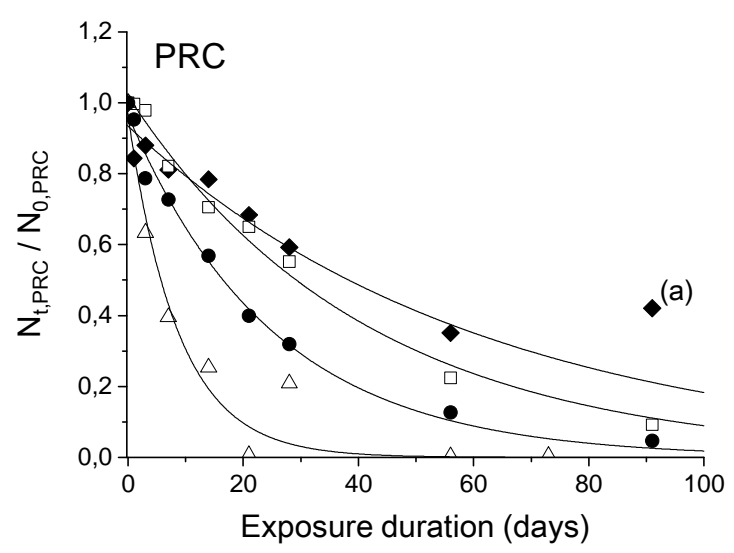


599 Fig. 2. Surface area normalized sampling rates $\left(R_{S A}, L . d^{-1} \cdot 100 \mathrm{~cm}^{-2}\right)$ of $P C B s$ in the five 600 integrative samplers. Error bars represent the standard deviations $(n=3)$. $R_{S A}$ was 601 normalized to a membrane surface area of $100 \mathrm{~cm}^{2}$. PCB congeners are on the $x$-axis. 602 PCBs approaching equilibrium are represented with grey bars.

603 PCB 157 could not be quantified in SPMD because of co-eluting peaks (ND). 604 605 
606
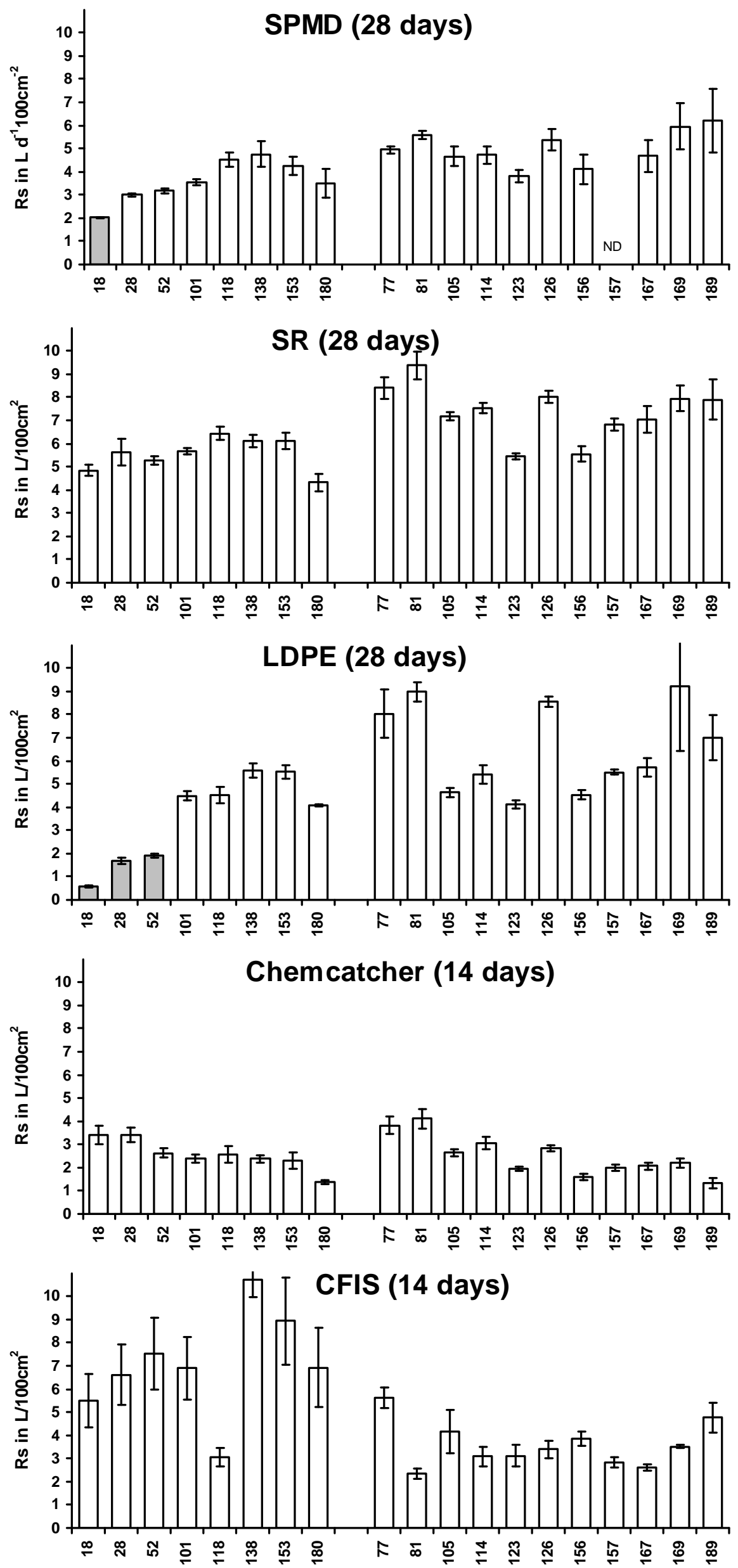

26 
607 Fig. 3. Ratios of the time-weighted average (TWA) concentrations of PCBs calculated from 608 integrative samplers on the PCB water concentrations calculated from dosing sheets. The 609 TWA concentrations were calculated as indicated in Table 2. PCB congeners are on the $x$ 610 axis.

611

612

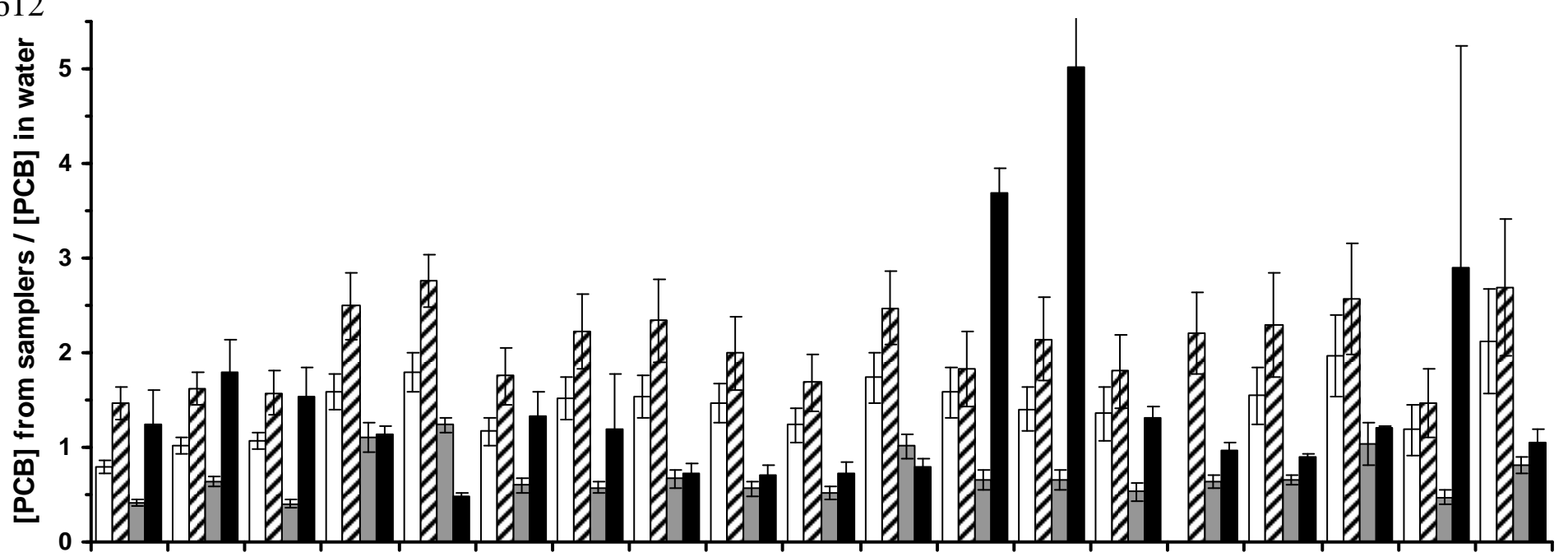

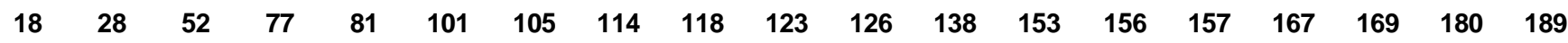
$\square$ SPMD $\square$ SR $\square$ LDPE strip $\square$ CFIS 
613 Fig. 4. Ratios of the time-weighted average (TWA) concentrations of PCBs calculated from 614 integrative samplers on the concentrations of PCBs in water. The TWA concentrations 615 were calculated as indicated in Table 2 (reference method) and by changing SPMD-water 616 partition coefficient values (for SPMD) and selection criteria of PRCs (for SPMD, SR and 617 LDPE strip). PCB congeners are on the $x$-axis.

618 ND: not determined (PCB 157 could not be quantified in SPMD because of co-eluting peaks). 619 620 621 622 623 624 625 626 627 628 629 630 631 632 633 634 635 


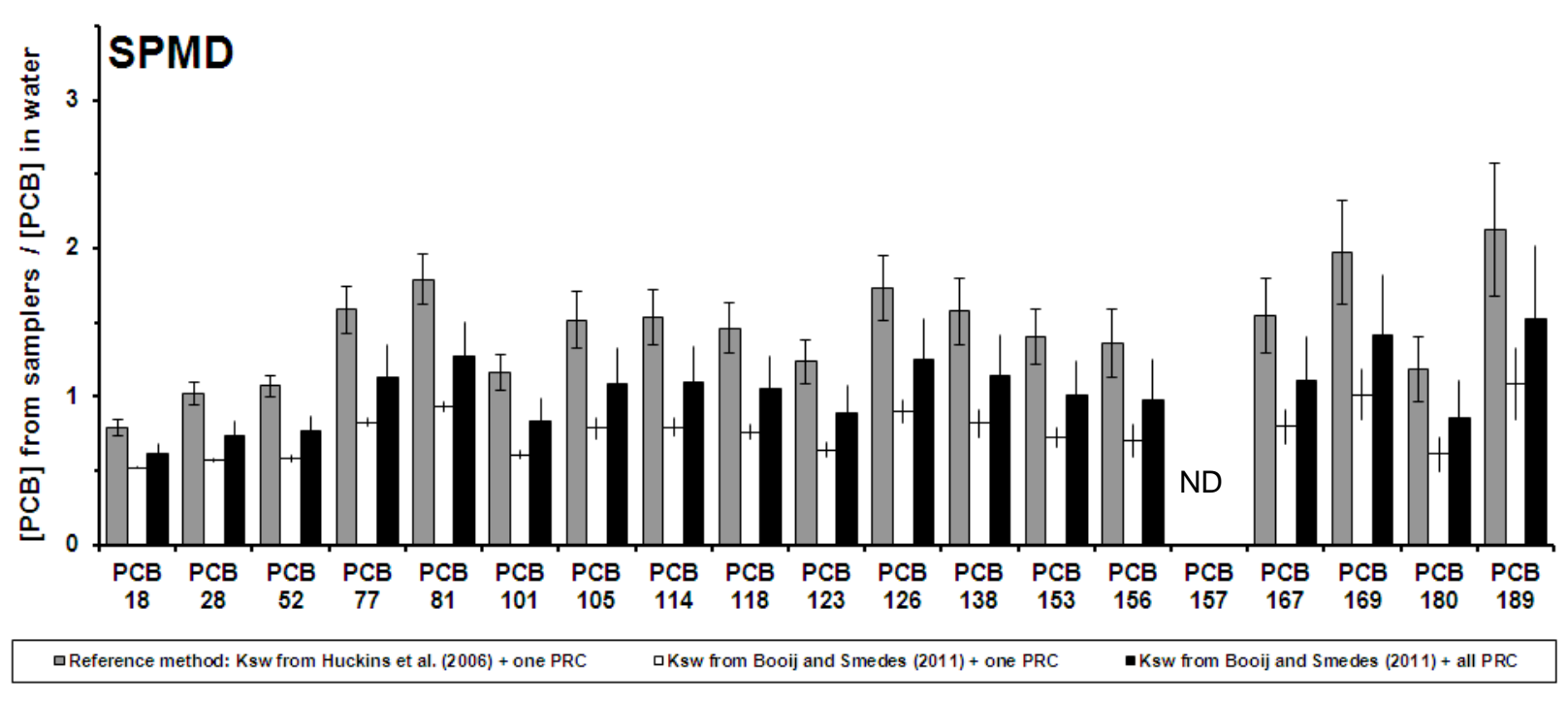

636
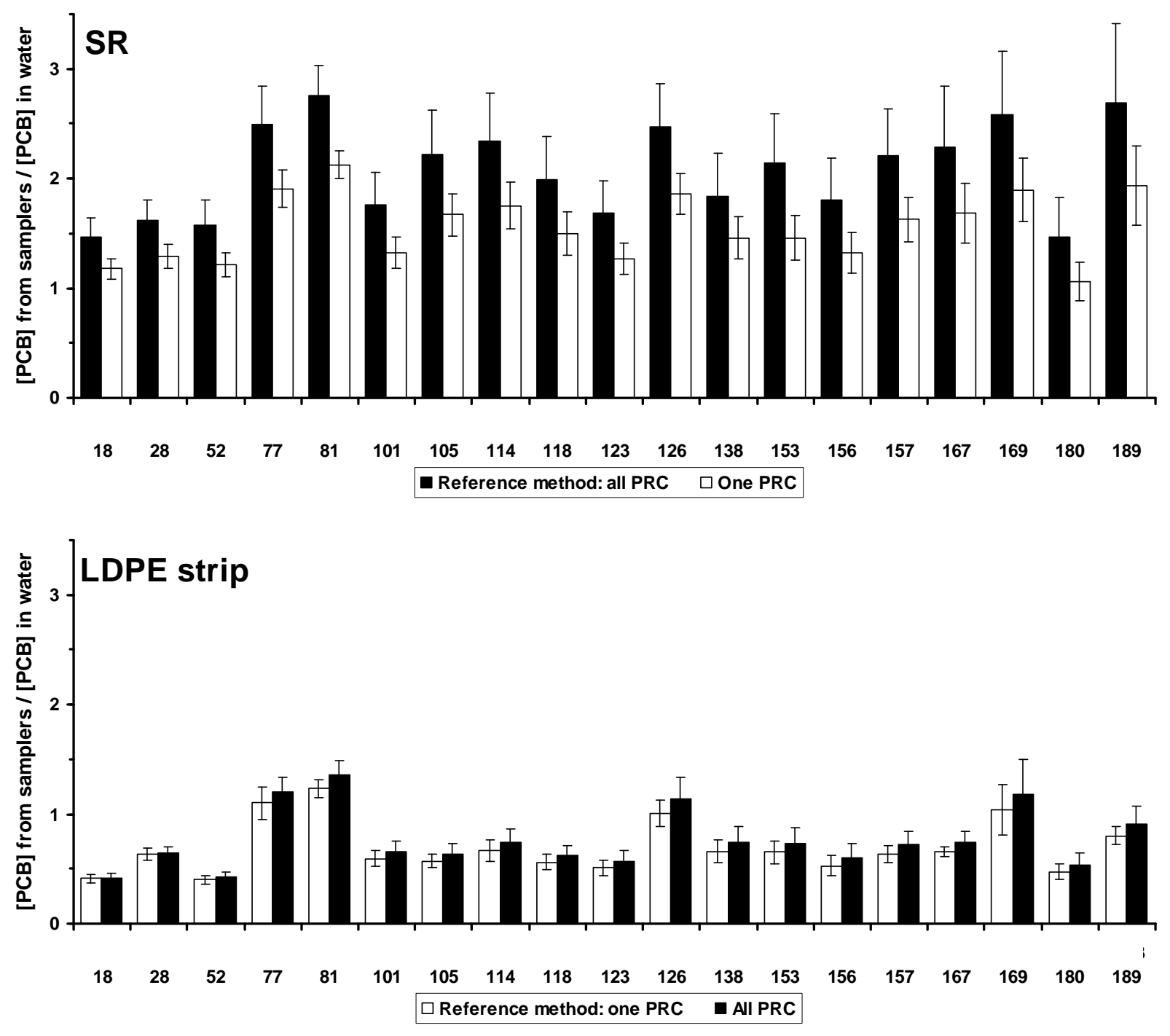
639 Table 1. Main characteristics and processing steps of the five integrative samplers

\begin{tabular}{|c|c|c|c|c|c|}
\hline & $\mathrm{SPMD}^{\mathrm{a}}$ & $\mathrm{SR}^{\mathrm{b}}$ & LDPE strip $^{c}$ & Chemcatcher $^{d}$ & $\mathrm{CFIS}^{\mathrm{e}}$ \\
\hline Suppliers & Exposmeter & $\begin{array}{l}\text { Altec Products } \\
\text { Limited }\end{array}$ & Brentwood plastics & $\begin{array}{l}\text { University of } \\
\text { Portsmouth }\end{array}$ & LABAQUA \\
\hline $\begin{array}{l}\text { Receiving phase } \\
\text { (membrane }{ }^{f}, \text { solid or } \\
\text { liquid phase) }\end{array}$ & LDPE + Triolein & PDMS & LDPE & $\begin{array}{l}\text { LDPE + C18 Empore } \\
\text { disk }+450 \mu \mathrm{L} \text { of } n- \\
\text { octanol }\end{array}$ & PDMS \\
\hline Surface area $\left(\mathrm{cm}^{2}\right)$ & 457 & 138 & 100 & 17 & 8 \\
\hline Weight $(\mathrm{g})$ & 4.5 & 4.1 & 0.39 & 0.62 & 0.144 \\
\hline Total volume $\left(\mathrm{cm}^{3}\right)$ & 4.95 & 3.4 & 0.425 & 0.6 & 0.147 \\
\hline PRC spiking method & $\begin{array}{l}\text { Syringe injection of } \\
\text { isooctane solution }\end{array}$ & $\begin{array}{l}\text { Soaking in water / } \\
\text { methanol solutions }\end{array}$ & $\begin{array}{l}\text { Soaking in water / } \\
\text { methanol solutions }\end{array}$ & $\begin{array}{l}\text { Percolation of } \\
\text { aqueous solution }\end{array}$ & No PRC \\
\hline $\mathrm{PRC}^{\mathrm{g}}$ & $\begin{array}{c}\text { PCB } 3,10,14,29 \\
37,55,78,104,155 \\
166,201,204\end{array}$ & $\begin{array}{c}\text { Bip-d10, PCB 1, 2, 3, } \\
\text { 10, 14, 21, 30, 50, } \\
55,78,104,145 \\
204\end{array}$ & $\begin{array}{c}\text { PCB 10, 14, 29, 104, } \\
112,204\end{array}$ & $\begin{array}{l}\text { Bip-d10, Ace-d10, } \\
\text { Flu-d10, Phe-d10, } \\
\text { Pyr-d10, B[a]a-d12 }\end{array}$ & / \\
\hline Extraction & $\begin{array}{l}\text { Dialysis in } \\
\text { cyclohexane }\end{array}$ & $\begin{array}{l}\text { Soxhlet with } \\
\text { methanol }\end{array}$ & Soaking in cyclohexane & $\begin{array}{l}\text { Ultrasonic bath in } \\
\text { acetone and ethyl } \\
\text { acetate / isooctane }\end{array}$ & Thermodesorption \\
\hline Analytical surrogate & $\begin{array}{c}\text { PCB 34, 119, } 141, \\
209\end{array}$ & $\begin{array}{c}{ }^{13} \mathrm{C} \text { labeled indicator } \\
\text { PCB, PCB } 143\end{array}$ & PCB $30,198,209$, TCN $^{h}$ & None & Flu-d10, Chry-d12 \\
\hline Purification & Florisil & None & Silica and alumina & None & None \\
\hline Analytical technique & GC-ECD & GC-MS & $\begin{array}{l}\text { GC-ECD for } \mathrm{PCB}_{\mathrm{i}} \\
\text { GC-HRMS for } \mathrm{PCB}_{\mathrm{dl}}\end{array}$ & GC-MS & GC-MS \\
\hline
\end{tabular}




\begin{tabular}{|c|c|c|c|c|c|}
\hline $\begin{array}{l}\text { Chromatographic } \\
\text { column }\end{array}$ & $\begin{array}{l}\text { Restek RTX-PCB } \\
\text { and RTX-5 }\end{array}$ & Alltech AT-5MS & $\begin{array}{c}\text { Agilent DB-5 and SGE } \\
\text { HT8 for PCB } \\
\text { SGE HT8 for } \mathrm{PCB}_{\mathrm{dl}}\end{array}$ & Varian CP-Sil 8 CB & $\begin{array}{c}\text { Teknokroma TRB- } \\
5 \mathrm{~ms}\end{array}$ \\
\hline
\end{tabular}

a SPMD: semipermeable membrane device, membrane length $=91.4 \mathrm{~cm}$, width $=2.5 \mathrm{~cm}$, thickness $=70-95 \mu \mathrm{m}$; triolein volume $=1 \mathrm{ml}$, weigth $=0.915 \mathrm{~g}$.

${ }^{\mathrm{b}} \mathrm{SR}$ : silicone rubber, length $=12.5 \mathrm{~cm}$, width $=5.5 \mathrm{~cm}$, thickness $=500 \mu \mathrm{m}$.

${ }^{c}$ LDPE strip: low-density polyethylene strip, length $=20 \mathrm{~cm}$, width $=2.5 \mathrm{~cm}$, thickness $=80 \mu \mathrm{m}$.

${ }^{d}$ Chemcatcher: non-polar version, membrane diameter $=4.7 \mathrm{~cm}$, thickness $=40 \mu \mathrm{m} ;$ C18 Empore disk diameter $=4.7 \mathrm{~cm}$, volume $=0.6 \mathrm{~mL}$ (i.e.

$0.45 \mathrm{~mL}$ octanol $+0.15 \mathrm{~mL}$ C18)

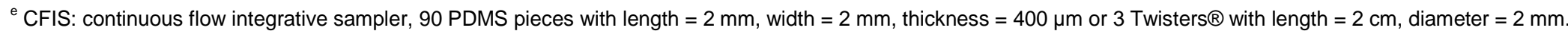

${ }^{\dagger}$ LDPE: low density polyethylene, PDMS: polydimethylsiloxane.

${ }^{9}$ PRCs: performance reference compounds, Bip: biphenyl, Ace: acenaphthene, Flu: fluorene, Phe: phenanthrene, Pyr: pyrene, B[a]a: benzo[a]anthracene.

${ }^{\mathrm{h}}$ TCN: 1,2,3,4-tetrachloronaphthalene 
640 Table 2. Strategies (models, criteria to select PRCs and methods to evaluate $\log K_{\mathrm{sw}}$ )

641 used for the calculation of TWA concentrations of PCBs in water for each integrative

642 sampler.

643

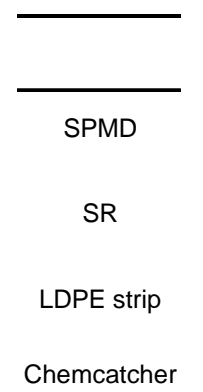

644

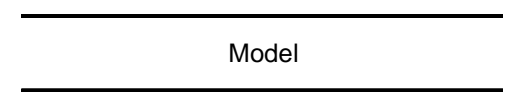

Huckins et al. 2006 (water boundary layer - controlled uptake model)

Rusina et al. 2010 (water boundary layer controlled uptake model)

Huckins et al. 2006 (water boundary layer - controlled uptake model)

Vrana et al. 2007 (applicable for compounds with $3.7<\log \mathrm{K}_{\mathrm{ow}}<6.8$ )

none, use of predetermined $R_{S}$ for $P C_{i}$

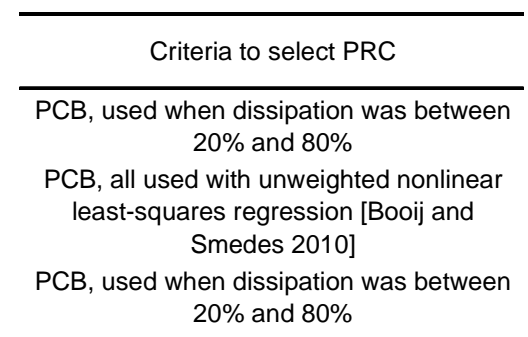

$\mathrm{PAH}$, used when dissipation was between $20 \%$ and $95 \%$
Methods to evaluate $\operatorname{LogK}_{\mathrm{sw}}$

empirical relationship function of $\log _{\text {ow }}$ [Huckins et al. 2006]

measured and modeled [Smedes et al. 2009]

measured and modeled [Smedes et al. 2009]

empirical relationship function of log $\mathrm{K}_{\mathrm{ow}}$ [Vrana et al. 2006]

none, not required

none, not required 


\section{Title}

2 Comparison of five integrative samplers in laboratory for the monitoring of indicator

3 and dioxin-like polychlorinated biphenyls in water

\section{Authors}

5 Romain Jacquet $^{a}$, Cécile Miège ${ }^{a *}$, Foppe Smedes ${ }^{b, c}$, Céline Tixier ${ }^{d}$, Jacek

6 Tronczynski $^{d}$, Anne Togola ${ }^{e}$, Catherine Berho ${ }^{e}$, Ignacio Valor ${ }^{f}$, Julio Llorca ${ }^{f}$, Bruno

$7 \quad$ Barillon $^{\mathrm{g}}, \mathrm{P}$ Marchand ${ }^{\mathrm{e}}$, Marina Coquery ${ }^{\mathrm{a}}$

8

9 Supplementary data (available online)

10 S1. Additional information about materials and methods

11 S2. Scheme of the exposure device

12 S3. Detailed calculations of TWA concentrations of PCBs in water

13 S4. Results of the physicochemical analysis of water sampled during exposure

14 S5. PRC-based linear uptake phase durations of PCBs

15 S6. PRC-based sampling rates of PCBs

16 
S1. Additional information about materials and methods

\section{S1.1. SPMD}

SPMD were purchased from Exposmeter (Tavelsjö, Sweden) and had the standard configuration, as defined by Huckins et al. (2006): an area-to-volume ratio of about $460 \mathrm{~cm}^{2} / \mathrm{ml}$ of triolein (purity $\geq 95 \%$ ), an approximate lipid-to-membrane mass ratio of 0.25 and a $70-95 \mu \mathrm{m}$ wall thickness.

Prior to their exposure, SPMD were spiked with several PRC (Table 1). The membrane was perforated at one end and $25 \mu \mathrm{l}$ of isooctane containing $4 \mathrm{mg} / \mathrm{L}$ of each PRC was injected with a $50 \mu \mathrm{l}$ syringe. Membrane was then heat-sealed and SPMD were stored in air tight cans at $-20^{\circ} \mathrm{C}$ until e xposure.

After exposure and retrieval, SPMD were stored in air tight cans at $-20^{\circ} \mathrm{C}$ until processing. Prior to extraction, mounting loops were cut and SPMD membranes were cleaned with Milli-Q water, wiped with paper and measured to determine their exact surface area. Recovery of accumulated PCBs was carried out by dialysis in $125 \mathrm{ml}$ of cyclohexane at $15^{\circ} \mathrm{C}$ during $24 \mathrm{~h}$ in darkness. This op eration was repeated one time. Dialysis was performed at $15^{\circ} \mathrm{C}$ in order to reduce the amount of co-extracted material (Meadows et al. 1993). Both dialysates were combined and after addition of internal surrogates (100 $\mathrm{ng}$ of PCBs 34, 119, 141 and 209), the solvent was evaporated to $1 \mathrm{ml}$. Then, extracts were diluted $(100 \mu \mathrm{l}$ completed to $1 \mathrm{ml}$ with cyclohexane) and purified on disposable Florisil cartridges $(6 \mathrm{ml}, 1 \mathrm{~g})$ conditioned with $10 \mathrm{ml}$ of cyclohexane. Extracts were loaded on the cartridges and allowed to soak during $5 \mathrm{~min}$ after which elution was performed with $10 \mathrm{ml}$ of cyclohexane/methylene chloride 95/5 (v/v). After evaporation under nitrogen with 10 $\mu \mathrm{l}$ of $\mathrm{n}$-dodecane, used as keeper, extracts were reconstituted in $1 \mathrm{ml}$ of isooctane 
containing $10 \mu \mathrm{g} / \mathrm{L}$ of 2,4,5,6-tetrachloro-m-xylene (TCX) and octachloronaphtalene $(\mathrm{OCN})$, used as internal standards.

Analysis of SPMD extracts were performed with a Varian (Les Ulis, France) 3800 GC-ECD using two chromatographic columns purchased from Restek (Lisses, France), a RTX-PCB column (30 m x $0.25 \mathrm{~mm} \times 0.25 \mu \mathrm{m})$ and a RTX-5 column (30 $\mathrm{m} \times 0.25 \mathrm{~mm} \times 0.25 \mu \mathrm{m})$. Both columns were equipped with $10 \mathrm{~m}$ of uncoated guardcolumns. PCB 157 could not be quantified because of co-eluting peaks on both columns. All results were corrected for recovery of internal surrogates.

\section{S1.2. Silicone rubber (SR)}

Silicone rubber sheets of $60 \times 60 \mathrm{~cm}$ and $0.5 \mathrm{~mm}$ thickness were purchased from Altec Products Limited (Cornwall, UK). From this large sheets sampler were prepared by cutting them at a size of $12.5 \times 5.5 \mathrm{~cm}$ and were soxhlet extracted with ethylacetate for $100 \mathrm{~h}$ prior to use.

To measure of the exchange rate through the release of PRC, 27 exposure sheets were spiked with PRC (Table 1). Spiking was done by soaking the sheets in methanol containing the PRC and followed by adding portions of water to gradually increase the water content (Smedes and Booij, 2012). The procedure is similar to that for the dosing sheets, but starting with $300 \mathrm{ml}$ of methanol. Time periods and methanol percentages were equal to the procedure described for dosing sheets (S1.6). After spiking, the sheets were washed with Milli-Q water, individually packed in diffusion closed glass jars numbered from 1 to 27 and stored at $-20^{\circ} \mathrm{C}$ when not exposed in the tank. After thawing, sheets were carefully wiped dry with a tissue before exposure. 
Prior to analysis of the bulk samples, a one day exposure sheet was analyzed

to allow estimation of appropriate dilutions ensuring later extracts to fit the calibration curve. Prior to extraction, each sheet was spiked with internal surrogates: $1000 \mathrm{ng}$ of PCB 143 and up to 28 days exposure, $10 \mathrm{ng}$ of ${ }^{13} \mathrm{C}$ labeled indicator PCB were added. One and three days exposures, that were performed four and two times, respectively, were considered as single exposures and extracted together. Exposed and unexposed sheets were soxhlet extracted by $120 \mathrm{ml}$ of methanol for 16 hours. Extracts were Kuderna-Danish evaporated until $2 \mathrm{ml}$ and $20 \mathrm{ml}$ of hexane were added. By Kuderna-Danish evaporation, the methanol was azeotropically removed and consequently the extract was transferred to hexane. Hexane extracts were further concentrated to $1 \mathrm{ml}$ using a gentle stream of nitrogen for short exposures and gradually diluted for longer exposures, up to $15 \mathrm{ml}$ of hexane for a $90 \mathrm{~d}$ exposure. To each extract TCN was added to obtain a concentration at $100 \mathrm{ng} / \mathrm{ml}$.

Extracts were analysed on an Agilent (Palo Alto, CA, USA) HP 6890 Series GC-MS with an Agilent HP 5973N mass selective detector. The column was an Allech AT-5MS (30 m x $0.25 \mathrm{~mm} \times 0.25 \mu \mathrm{m})$ from Grace (Deerfield, IL, USA). Selected Ion Monitoring (SIM) mode was applied for quantification using appropriate masses and two masses were monitored for each PCB. All calculations were done based on TCN as an internal standard.

\section{S1.3. LDPE strips}

LDPE strips were prepared from additive-free LDPE lay-flat tubing purchased from Brentwood plastics (MO, USA). Single layered strips were obtained by cutting sections of the tubing twice along the side edges. A mounting loop was prepared at each extremity of the strips and removed before the whole analytical treatment. 
Prior to use, LDPE strips were pre-extracted twice by soaking in cyclohexane overnight and then spiked with six PRC (Table 1) following the method described by Booij et al. (2002). Briefly, LDPE strips were soaked overnight in a PRC solution in methanol/water $80 / 20(\mathrm{v} / \mathrm{v})$. Spiked strips were stored at $-20^{\circ} \mathrm{C}$ until exposure. After exposure, LDPE strips were kept in the dark at $-20^{\circ} \mathrm{C}$ until further water. Strips were then extracted twice by soaking overnight in cyclohexane. Surrogate standards (PCBs 30, 198, 209 and TCN) were spiked into cyclohexane at the beginning of the extraction. After extraction, strips were removed from cyclohexane and allowed to dry for weight determination. The combined cyclohexane extract was concentrated to $4 \mathrm{ml}$ and an aliquot of $200 \mu \mathrm{l}$ was taken for dioxin-like

103 PCB analysis. The exact volume was controlled gravimetrically by weighting both extracts. The analytical protocols for cleanup and analysis of indicator PCBs and PRCs have been described previously (Johansson et al. 2006). Briefly, the clean-up and fractionation of all extracts were made by adsorption chromatography on a two layer silica/alumina column. The first fraction eluted with hexane was analysed for

108 PCB by GC-ECD according to the procedure described earlier (Johansson et al. 2006). For dioxin-like PCB analysis, separation of coplanar (non-ortho) PCB from non-planar PCB was achieved on an activated mixture of Florisil/Carbopack C/Celite 111545.

Analysis of LDPE extracts for indicator PCBs were performed with a Varian

113 (Les Ulis, France) 3800 GC fitted with two electron capture detector and two columns 114 of different polarities: a DB-5 column $(60 \mathrm{~m} \times 0.25 \mathrm{~mm} \times 0.25 \mu \mathrm{m})$ from Agilent (Palo 115 Alto, CA, USA) and a HT8 column (50 m x $0.25 \mathrm{~mm} \times 0.25 \mu \mathrm{m})$ from SGE Europe Ltd 116 (Milton Keynes, UK). All PCB congeners were quantified on both columns and the 
117 reported result was chosen for each non-coeluting congener on the appropriate

118 column. Dioxin-like PCB analysis were conducted at LABERCA laboratory (Nantes,

119 France) according the method of Costera et al. (2006). Separation of coplanar (non-

120 ortho) PCBs from non-planar PCBs was achieved on an activated mixture of

121 Florisil/Carbopack C/Celite 545. Analyses were performed by GC-HRMS (gas

122 chromatograph (HP-7890) from Hewlett Packard -Palo Alto, CA, USA; mass

123 spectrometer (JMS-800D) from Jeol - Japan) equipped with a a HT8-PCB capillary

124 column $(60 \mathrm{~m} \times 0.25 \mathrm{~mm} \times 0.25 \mu \mathrm{m})$ from SGE Analytical Science (Australia).

\section{S1.4. Chemcatcher}

Chemcatchers were purchased from the University of Portsmouth and were prepared according to their own protocol (University of Portsmouth, 2009).

Before use, C18 Empore disks were soaked in methanol overnight in a clean

130 glass beaker. Then, they were placed on a $47 \mathrm{~mm}$ diameter disk vacuum manifold

131 platform and $50 \mathrm{ml}$ of methanol were slowly passed through the disks, followed by

$132150 \mathrm{ml}$ of ultrapure water. Then $250 \mathrm{ml}$ of water spiked with $300 \mu \mathrm{l}$ of PRC (Table 1)

133 standard solution at $2 \mu \mathrm{g} / \mathrm{ml}$ in methanol was filtered through the disks. The Empore

134 disks were then dried under vacuum during $30 \mathrm{~min}$ and put on the sampler PTFE

135 supports. Then, $1 \mathrm{ml}$ of $45 \%(\mathrm{v} / \mathrm{v}) \mathrm{n}$-octanol in methanol was applied evenly to the

136 surface of each C18 Empore disk. The resulting volume of n-octanol was $450 \mu$. The

137 LDPE membranes (pre-cleaned by soaking in $\mathrm{n}$-hexane during $24 \mathrm{~h}$ and dried) were

138 put on the top and any air bubbles were smoothed away from between the two layers

139 by gently pressing the top surface of the membrane using a clean paper tissue. The

140 PTFE supporting disks were placed in the sampler bodies and fixed in place to form 
141 a watertight seal between the membrane and the top section of the sampler (Vrana

142 et al. 2005; Vrana et al. 2006). Chemcatchers were stored at -20C until exposure.

143 After exposure, samplers were rinsed with ultrapure water, carefully

144 disassembled and LDPE membranes were removed and rinsed with acetone. PCBs

145 were extracted from the Empore disks with 5 min of ultrasonic bath in acetone

146 followed by $5 \mathrm{~min}$ in ethyl acetate/2,2,4-trimethylpentane 50/50 (v/v). The disks were

147 then removed and the solvent extracts, combined with the LDPE membrane rinsates,

148 were filtered through a drying cartridge containing sodium sulfate. Extracts were

149 reduced under nitrogen at $450 \mu \mathrm{l}$ and transferred to $2 \mathrm{ml}$ vials prior to analysis with a

150 solution of chrysene-d12 (internal standard) in n-octanol. The final volume was

151 adjusted to $500 \mu \mathrm{l}$ with n-octanol (University of Portsmouth, 2009; Vrana et al. 2005).

152 Sampler extracts were analysed with a Varian (Les Ulis, France) 240 GC-

$153 \mathrm{MS} / \mathrm{MS}$ system using a Varian CP-SIL $8 \mathrm{CB}(50 \mathrm{~m} \times 0.25 \mathrm{~mm} \times 0.25 \mu \mathrm{m})$ capillary

154 column equipped with a guard-column.

156 S1.5. CFIS

157 The CFIS device was developed by Labaqua and was prepared with PDMS 158 pieces or PDMS in Twister ${ }^{\circledR}$ format from Gerstel (Mülheim an der Ruhr, Germany).

159 The PDMS pieces were obtained by cutting a PDMS tubing in pieces of $2 \times 2 \mathrm{~mm}$.

160 Every device contains 90 PDMS pieces or 3 Twisters ${ }^{\circledR}$. Prior to use, Twisters ${ }^{\circledR}$ were

161 conditioned in an empty thermodesorption tube at $300^{\circ} \mathrm{C}$ for $4 \mathrm{~h}$ with an helium flow 162 of $75 \mathrm{ml} / \mathrm{min}$. After exposure, the Twisters $^{\circledR}$ or PDMS pieces were removed from the CFIS, 164 gently dried with a paper tissue and finally introduced in glass desorption tubes. 
Analysis were performed by thermodesorption-GC-MS using an Agilent (Palo

166 Alto, CA, USA) 6890 GC - 5973 MS system equipped with a Gerstel thermal

167 desorption unit TDS-2 and connected to a Gerstel programmed-temperature 168 vaporization (PTV) injector CIS-4 Plus by a heated transfer line. Analysis were 169 carried out using an TRB- $5 \mathrm{~ms}$ column $(30 \mathrm{~m} \times 0.25 \mathrm{~mm} \times 0.25 \mu \mathrm{m})$ from Teknokroma 170 (Barcelona, Spain).

171

\section{S1.6. Dosing sheets}

Silicone rubber sheets of $60 \times 60 \mathrm{~cm}$ purchased from Altec Products Limited

174 (Cornwall, UK) were cut in pieces of $5 \times 15 \mathrm{~cm}$ and four holes were pinched in the 4-

$17512 \mathrm{~cm}$ middle part. A total of $1.1 \mathrm{~kg}$ of dosing sheets, corresponding to a surface area

176 of around $3.5 \mathrm{~m}^{2}$, were prepared this way. Prior to use, sheets were soxhlet extracted

177 with ethylacetate for one week and subsequently, the ethylacetate was extracted

178 from the sheets by two times $4 \mathrm{~h}$ with $2 \mathrm{~L}$ of methanol. Then the dosing sheets were

179 immersed in $1.6 \mathrm{~L}$ of methanol and the custom-made spiking solution obtained from

180 CIL Cluzeau (Courbevoie, France) was added. This solution contained PCB 18 (0.34

$181 \mathrm{mg})$, PCB 28 (0.60 mg), РCB 52 (0.9 mg), РCB 77 (2.2 mg), РCB 81 (3.3 mg), РCB

182101 (2.28 mg), PCB 105 (2.6 mg), PCB 114 (9.6 mg), PCB 118 (2.6 mg), PCB 123

183 (2.7 mg), PCB 126 (3 mg), PCB 138 (6 mg), PCB 153 (5 mg), PCB 156 (5 mg), PCB

184157 (7 mg), PCB 167 (8 mg), PCB 169 (10 mg), PCB 180 (10 mg), PCB 189 (7 mg)

185 in $5 \mathrm{ml}$ of ethylacetate. After $6 \mathrm{~h}$ of shaking, water was added to obtain a $90 \%$

186 methanol solution that was shaken for $32 \mathrm{~h}$. Dilution with water was continued by

$18710 \%$ steps as follows: $36 \mathrm{~h}$ at $80 \%, 48 \mathrm{~h}$ at $70 \%, 56 \mathrm{~h}$ at $60 \%$ and $80 \mathrm{~h}$ at $50 \%$

188 methanol. Then the water/methanol mixture was discarded and sheets were washed 
189 once with milli-Q water. Two quality control samples were taken just after spiking and

190 another one after the mounting of dosing sheets in the tank.

191 Before analysis, samples of dosing sheets were stored in glass jars at $-20^{\circ} \mathrm{C}$.

192 For each analysis, about $1 \mathrm{~g}$ of dosing sheet was extracted with $50 \mathrm{ml}$ of methanol in

193 a glass jar with an aluminum foil lined lid shaked overnight at $100 \mathrm{rpm}$. Prior to

194 extraction, $1000 \mathrm{ng}$ of PCB 143 was added as an internal surrogate. The extraction

195 was repeated and the combined extract was Kuderna Danish evaporated to about 2

$196 \mathrm{ml}$ followed by addition of $20 \mathrm{ml}$ of hexane and Kuderna Danish evaporation was

197 repeated. The obtained hexane extract was transferred to a $15 \mathrm{ml}$ vial and brought to

$19810 \mathrm{ml}$ on weight basis. From the extract, $1 \mathrm{ml}$ (on weight basis) was transferred to a

199 vial and $100 \mathrm{ng}$ of TCN (1,2,3,4-tetrachloronaphtalene) were added. Further, a

200 dilution was made by measuring $100 \mu \mathrm{l}$ into a vial with $100 \mathrm{ng}$ of TCN and adding 201 hexane to $1 \mathrm{ml}$. Extracts were analysed as described for silicone rubber exposure 202 sheets (S1.2). 
204 S2. Scheme and pictures of the exposure device (height $=120 \mathrm{~cm}$, diameter $=47$

$205 \mathrm{~cm})$.
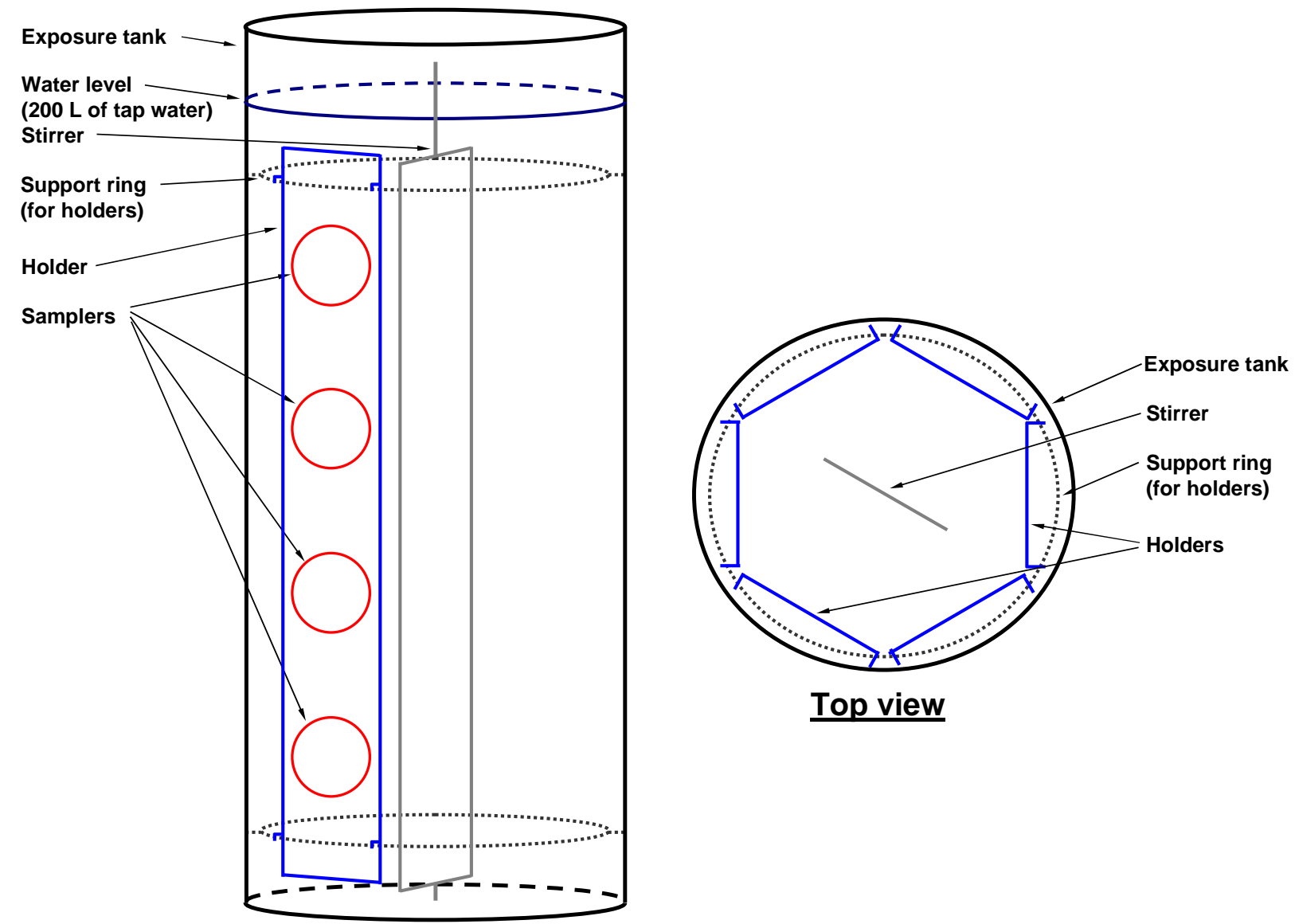

Side view

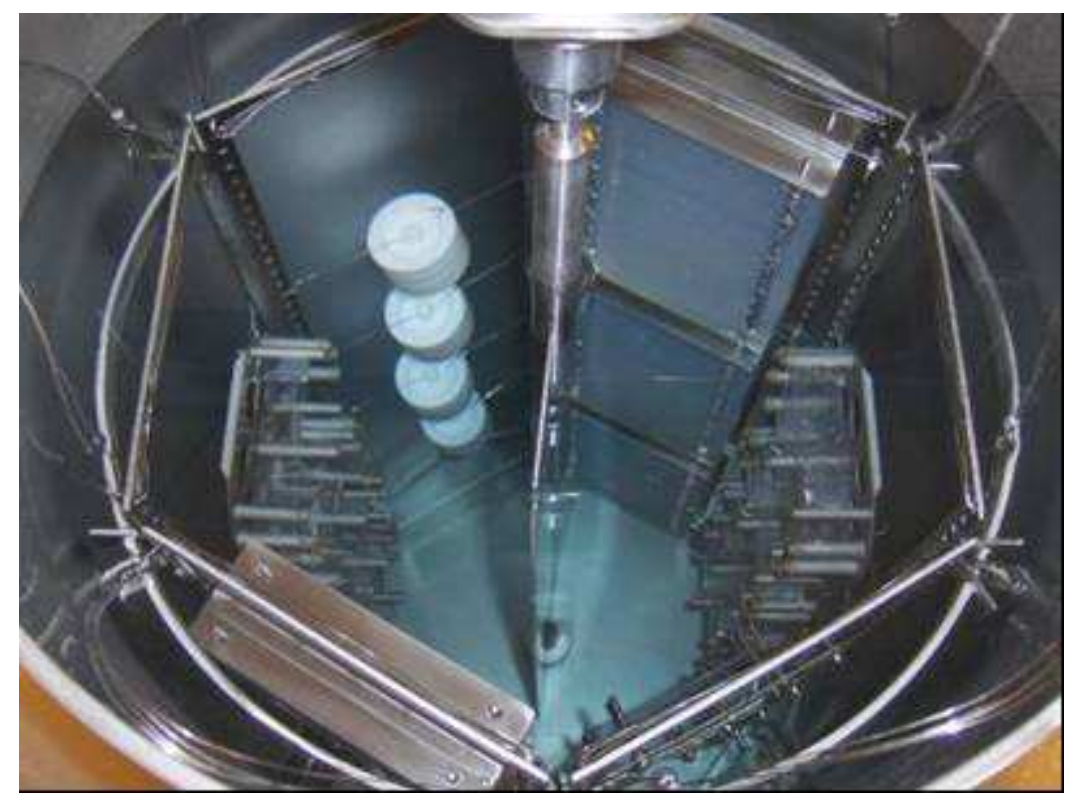

\section{$208 \underline{\text { Top view }}$}



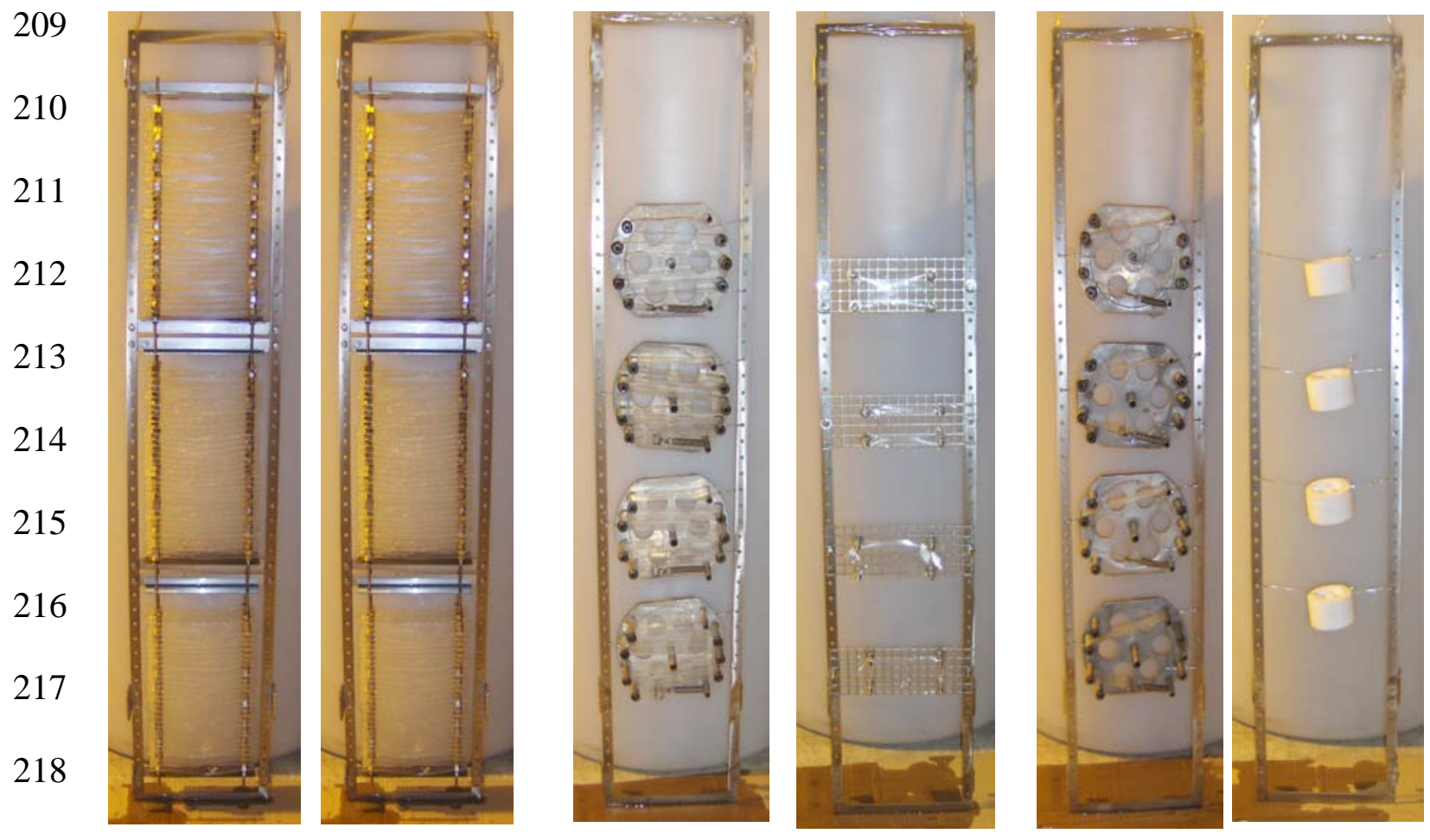

219

The six holders with passive samplers (from the left to the right : 2 dosing sheets as

221 source of contamination, 1 SPMD, 1 SR, 1 LDPE, 1 Chemcatcher)

222

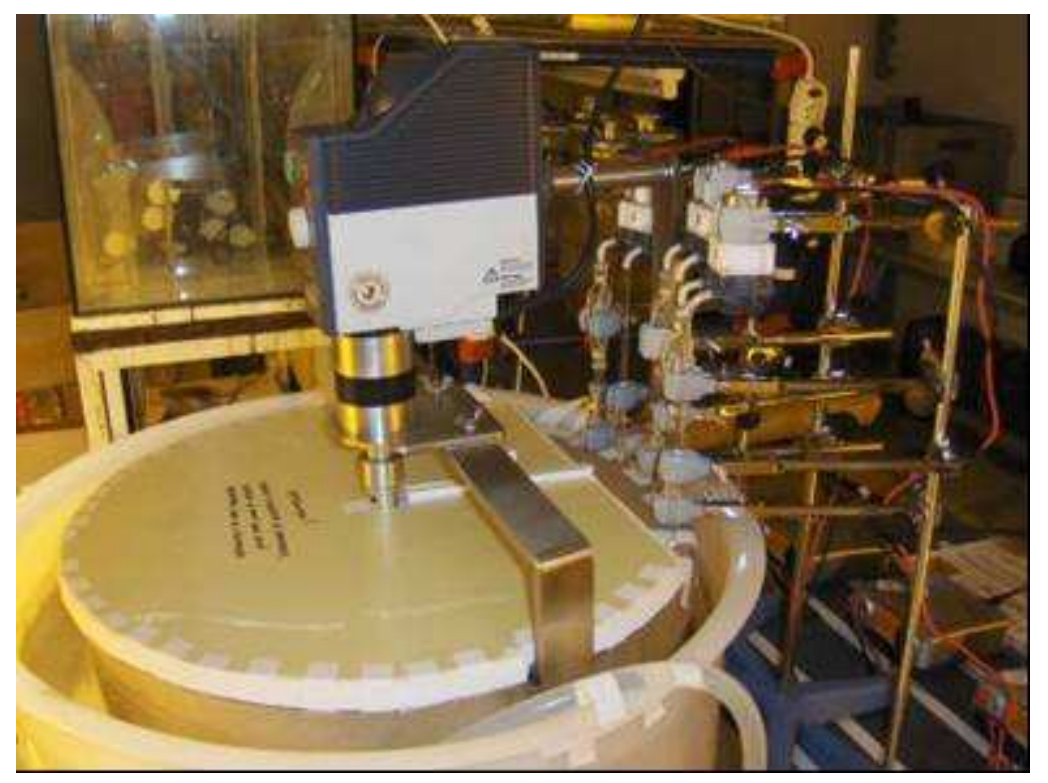

224 CFIS outside the tank 
$N_{t, i}$ : amount of compound i accumulated in the sampler at time $\mathrm{t}$

$230 \quad V_{s}:$ volume of sampler

$231 \quad V_{i}$ : molecular volume of compound $\mathrm{i}$

$232 M_{s}$ : mass of the sampler

$233 K_{o w, i}$ : octanol-water partition coefficient of compound $\mathrm{i}$

$234 A_{s}$ : surface area of the sampler

$235 \quad M W_{i}$ : molecular weight of compound $\mathrm{i}$

S3.1. SPMD

1. Calculation of PRC release rate constant, $k_{e, P R C}\left(\right.$ day $\left.^{-1}\right)$ :

240

$$
k_{e, P R C}=-\frac{\ln \left(N_{t, P R C} / N_{0, P R C}\right)}{t}
$$

242 2. Calculation of SPMD-water partition coefficient, $K_{s w, i}$ [Huckins et al. 2006]:

$243 \log K_{S W, i}=-2.61+2.321 \log K_{O W, i}-0.1618\left(\log K_{O W, i}\right)^{2}$

245 3. Calculation of PRC sampling rate, $R_{S, P R C}($ L.day-1):

$246 \quad R_{S, P R C}=V_{S} K_{S W, P R C} k_{e, P R C}$

248 4. Calculation of analyte i sampling rate, $R_{S, i}($ L.day-1):

$249 \quad R_{S, i}=R_{S, P R C}\left(\frac{V_{P R C}}{V_{i}}\right)^{0.39}$ 
5. Calculation of analyte time-weighted average concentration in water, $C_{W, i}(\mathrm{ng} / \mathrm{L})$ :

252

$$
C_{W, i}=\frac{N_{t, i}}{V_{S} K_{S W, i}\left(1-\exp \left(-\frac{R_{S, i} t}{V_{S} K_{S W, i}}\right)\right)}
$$

253

254 6. Calculation of analyte linear uptake phase duration, $t_{1 / 2, i}($ day):

$255 \quad t_{1 / 2, i}=\frac{\ln 2 V_{S} K_{S W, i}}{R_{S, i}}=\frac{\ln 2}{k_{e, i}}$

S3.2. $S R$

259

1. Estimation of $F$ through nonlinear regression by fitting the measured release of

261 PRC with modeled data as a function of $K_{\mathrm{pw}}$ and $M W^{0.47}$. [Booij and Smedes, 2010]

$$
N_{t, P R C} / N_{0, P R C}=\exp \left(-\frac{A_{S} M W_{P R C}^{-0.47} F t}{M_{S} K_{P W}}\right)
$$

2. Calculation of analyte time-weighted average concentration in water, $C_{W, i}(\mathrm{ng} / \mathrm{L})$ :

$$
C_{W, i}=\frac{N_{t, i}}{M_{S} K_{P W}\left(1-\exp \left(-\frac{A_{S} M W_{i}^{-0.47} F t}{M_{S} K_{P W}}\right)\right)}
$$

3. Calculation of analyte linear uptake phase duration, $t_{1 / 2, i}$ (day):

268

$$
t_{1 / 2, i}=\frac{\ln 2 M_{S} K_{P W, i}}{A_{S} M W^{-0.47} F}=\frac{\ln 2}{k_{e, i}}
$$


271 S3.3. LDPE

272

273 1. Calculation of PRC release rate constant, $k_{e, P R C}\left(\right.$ day $\left.^{-1}\right)$ :

$274 \quad k_{e, P R C}=-\frac{\ln \left(N_{t, P R C} / N_{0, P R C}\right)}{t}$

275

276 2. Calculation of LDPE-water partition coefficient, $K_{P W, i}$ [Smedes et al. 2009]:

$277 \log K_{P W, i}=0.0141 M W_{i}+0.90 M P F_{i}+1.06(+0.21$ for tetra-ortho substituted PCB $)$

278 (with $M P F=\frac{\text { number of }(\text { meta }+ \text { para }) \text { chlorine atoms }}{\text { total number of chlorine atoms }}$, meta-para chlorine fraction)

279

280 3. Calculation of PRC sampling rate, $R_{S, P R C}($ L.day-1):

$281 \quad R_{S, P R C}=M_{S} K_{P W, P R C} k_{e, P R C}$

282

283 4. Calculation of analyte i sampling rate, $R_{S, i}($ L.day-1):

$284 \quad R_{S, i}=R_{S, P R C}\left(\frac{V_{P R C}}{V_{i}}\right)^{0.39}$

285

286 5. Calculation of analyte time-weighted average concentration in water, $C_{W, i}(\mathrm{ng} / \mathrm{L})$ :

287

$$
C_{W, i}=\frac{N_{t, i}}{M_{S} K_{P W, i}\left(1-\exp \left(-\frac{R_{S, i} t}{M_{S} K_{P W, i}}\right)\right)}
$$

288

289 6. Calculation of analyte linear uptake phase duration, $t_{1 / 2, i}$ (day): 
$290 \quad t_{1 / 2, i}=\frac{\ln 2 M_{S} K_{P W, i}}{R_{S, i}}=\frac{\ln 2}{k_{e, i}}$

\section{S3.4. Chemcatcher}

294

295 1. Calculation of PRC release rate constant, $k_{e, P R C}\left(\right.$ day $\left.^{-1}\right)$ :

$296 \quad k_{e, P R C}=-\frac{\ln \left(N_{t, P R C} / N_{0, P R C}\right)}{t}$

298 2. Calculation of Chemcatcher-water partition coefficient, $K_{D W, i}$ [Vrana 2006]:

$299 \quad \log K_{D W, i}=1.382 \log K_{O W, i}-1.77$

300

301 3. Calculation of PRC sampling rate, $R_{S, P R C}($ L.day-1):

$302 \quad R_{S, P R C}=V_{S} K_{D W, P R C} k_{e, P R C}$

303

304 4. Calculation of analyte sampling rate, $R_{S, i}$ (L.day-1) [Vrana 2007]:

$305 \log R_{S, i}=P_{i}+22.755 \log K_{O W, i}-4.061\left(\log K_{O W, i}\right)^{2}+0.2318\left(\log K_{O W, i}\right)^{3}$

$306 P i$ : a factor taking into account environmental conditions and determined from $R_{s}$ of

307 PRC $\left[\mathrm{Pi}=\log R_{s, P R C}-22.775 \log K_{\text {ow,PRC }}+4.061\left(\log K_{\text {ow,PRC}}\right)^{2}-0.2318(\log \right.$ $\left.\left.308 K_{\text {ow }, P R C}\right)^{3}\right]$

309

5. Calculation of analyte time-weighted average concentration in water, $C_{W, i}(\mathrm{ng} / \mathrm{L})$ : 
311

$$
C_{W, i}=\frac{N_{t, i}}{V_{S} K_{D W, i}\left(1-\exp \left(-\frac{R_{S, i} t}{V_{S} K_{D W, i}}\right)\right)}
$$

312

313 6. Calculation of analyte linear uptake phase duration, $t_{1 / 2, i}$ (day):

$314 \quad t_{1 / 2, i}=\frac{\ln 2 V_{S} K_{D W, i}}{R_{S, i}}=\frac{\ln 2}{k_{e, i}}$

317 S3.5. CFIS

318

319 1. Calculation of analyte time-weighted average concentration in water, $C_{W, i}(\mathrm{ng} / \mathrm{L})$ :

$320 \quad C_{W}=\frac{N_{t, i}}{R_{S, i} t}$

321

322 2. Calculation of analyte linear uptake phase duration, $t_{1 / 2, i}$ (day):

$323 \quad t_{1 / 2, i}=\frac{\ln 2 V_{S} K_{S W, i}}{R_{S, i}}=\frac{\ln 2}{k_{e, i}}$ 
325 S4. Results of the physicochemical analysis of water sampled during exposure 326

\begin{tabular}{ccccc}
\hline Day & Temperature $\left({ }^{\circ} \mathrm{C}\right)$ & $\mathrm{pH}$ & Conductivity $(\mu \mathrm{S} / \mathrm{cm})$ & DOC $^{\mathrm{a}}(\mathrm{mg} / \mathrm{L})$ \\
\hline D0 & 22.61 & 7.7 & 380 & 1.50 \\
D3 & 22.61 & 7.3 & 380 & 1.20 \\
D7 & 22.61 & 7.8 & 375 & 1.90 \\
D17 & 22.61 & 7.5 & 375 & 1.35 \\
D21 & 22.63 & 7.5 & 380 & 1.80 \\
D28 & 22.60 & 7.7 & 375 & 3.25 \\
D42 & 22.60 & 7.2 & 355 & 4.50 \\
D56 & 22.59 & 7,0 & 325 & 5.15 \\
D70 & 22.65 & 7.5 & 320 & 5.15 \\
D91 & 22.65 & 7.6 & 310 & 4,70 \\
\hline
\end{tabular}

327

${ }^{a}$ DOC: dissolved organic carbon

328

329 
330 S5. PRC-based linear uptake phase durations of PCBs (days)

331

\begin{tabular}{lcccc} 
& Log K ${ }^{a}$ & SPMD & SR & LDPE strip \\
\cline { 2 - 5 } PCB 18 & 5.24 & 27 & 43 & 3 \\
PCB 28 & 5.67 & 46 & 84 & 5 \\
PCB 52 & 5.84 & 57 & 159 & 12 \\
PCB 77 & 6.36 & 86 & 318 & 34 \\
PCB 81 & 6.36 & 86 & 318 & 34 \\
PCB 101 & 6.38 & 90 & 473 & 47 \\
PCB 105 & 6.65 & 103 & 661 & 70 \\
PCB 114 & 6.65 & 103 & 610 & 70 \\
PCB 118 & 6.74 & 106 & 653 & 70 \\
PCB 123 & 6.74 & 106 & 610 & 70 \\
PCB 126 & 6.89 & 110 & 819 & 107 \\
PCB 138 & 6.83 & 112 & 1306 & 170 \\
PCB 153 & 6.92 & 114 & 1459 & 170 \\
PCB 156 & 7.18 & 117 & 1305 & 239 \\
PCB 157 & 7.18 & 117 & 1649 & 239 \\
PCB 167 & 7.27 & 116 & 1649 & 239 \\
PCB 169 & 7.42 & 114 & 2108 & 338 \\
PCB 180 & 7.36 & 118 & 2437 & 589 \\
PCB 189 & 7.71 & 108 & 4395 & 795 \\
\hline
\end{tabular}

${ }^{a}$ values from Hawker and Connell (1988) 
334 S6. PRC-based sampling rates of PCBs (L/day $/ 100 \mathrm{~cm} 2)$

335

\begin{tabular}{cccr}
\hline Log K $_{\text {OW }}{ }^{a}$ & SPMD & SR & LDPE strip \\
\hline 5.24 & $3.6 \pm 0.3$ & $4.2 \pm 0.7$ & $10.0 \pm 1.2$ \\
5.67 & $3.6 \pm 0.3$ & $4.2 \pm 0.7$ & $10.0 \pm 1.2$ \\
5.84 & $3.5 \pm 0.3$ & $4.0 \pm 0.6$ & $9.6 \pm 1.2$ \\
6.36 & $3.5 \pm 0.3$ & $4.0 \pm 0.6$ & $9.6 \pm 1.2$ \\
6.36 & $3.5 \pm 0.3$ & $4.0 \pm 0.6$ & $9.6 \pm 1.2$ \\
6.38 & $3.4 \pm 0.3$ & $3.8 \pm 0.6$ & $9.4 \pm 1.2$ \\
6.65 & $3.4 \pm 0.3$ & $3.8 \pm 0.6$ & $9.4 \pm 1.2$ \\
6.65 & $3.4 \pm 0.3$ & $3.8 \pm 0.6$ & $9.4 \pm 1.2$ \\
6.74 & $3.4 \pm 0.3$ & $3.8 \pm 0.6$ & $9.4 \pm 1.2$ \\
6.74 & $3.4 \pm 0.3$ & $3.8 \pm 0.6$ & $9.4 \pm 1.2$ \\
6.89 & $3.4 \pm 0.3$ & $3.8 \pm 0.6$ & $9.4 \pm 1.2$ \\
6.83 & $3.3 \pm 0.3$ & $3.6 \pm 0.6$ & $9.1 \pm 1.2$ \\
6.92 & $3.3 \pm 0.3$ & $3.6 \pm 0.6$ & $9.1 \pm 1.2$ \\
7.18 & $3.3 \pm 0.3$ & $3.6 \pm 0.6$ & $9.1 \pm 1.2$ \\
7.18 & $3.3 \pm 0.3$ & $3.6 \pm 0.6$ & $9.1 \pm 1.2$ \\
7.27 & $3.3 \pm 0.3$ & $3.6 \pm 0.6$ & $9.1 \pm 1.2$ \\
7.42 & $3.3 \pm 0.3$ & $3.6 \pm 0.6$ & $9.1 \pm 1.2$ \\
7.36 & $3.2 \pm 0.3$ & $3.4 \pm 0.6$ & $8.9 \pm 1.2$ \\
7.71 & $3.2 \pm 0.3$ & $3.4 \pm 0.6$ & $8.9 \pm 1.2$ \\
\hline
\end{tabular}

a values from Hawker and Connell (1988) 


\section{References}

339 Costera, A. , Feidt, C., Marchand, P., Le Bizec, B., Rychen, G. 2006. PCDD/F and

340 PCB transfer to milk in goats exposed to long-term intake of contaminated hay.

341 Chemosphere 64, 650-657.

343 Booij, K., Smedes, F., van Weerlee, E.M., 2002. Spiking of performance reference 344 compounds in low density polyethylene and silicone passive water samplers. 345 Chemosphere 46, 1157-1161.

347 Booij, K, Smedes, F, 2010. An Improved Method for Estimating in Situ Sampling 348 Rates of Nonpolar Passive Samplers. Environ. Sci. Technol. 44(17), 6789-6794.

350 Hawker, D.W., Connell, D.W., 1988. Octanol water partition-coefficients of 351 polychlorinated biphenyl congeners. Environ. Sci. Technol. 22, 382-387.

353 Huckins, J.N., Petty, J.D., Booij, K., 2006. Monitors of organic chemicals in the 354 environment. Springer, New-York.

356 Johansson, I., Heas-Moisan, K., Guiot, N., Munschy, C., Tronczynski, J., 2006. 357 Polybrominated diphenyl ethers (PBDEs) in mussels from selected French coastal 358 sites: 1981-2003. Chemosphere 64, 296-305.

360 Meadows, J., Tillitt, D., Hickins, J., Schroeder, D., 1993. Large-scale dialysis of 361 sample lipids using a semi-permeable membrane device. Chemosphere 26, 19933622006. 
364 Smedes, F., Geertsma, R.W., Van der Zande, T., Booij, K., 2009. Polymer-water 365 partition coefficients of hydrophobic compounds for passive sampling: application of 366 cosolvent models for validation. Environ. Sci. Technol. 43, 7047-7054.

368 Smedes, F., and Booij, K., 2012. Guidelines for passive sampling of hydrophobic 369 contaminants in water using silicone rubber samplers. ICES Techniques in Marine 370 Environmental Sciences No. 52. 20 pp.

372 University of Portsmouth, 2009. The non-polar Chemcatcher® sampling device 373 Handling protocol.

375 Vrana, B., Mills, G.A., Greenwood, R., Knutsson, J., Svenssone, K., Morrison, G., 2005. Performance optimisation of a passive sampler for monitoring hydrophobic 377 organic pollutants in water. J. Environ. Monit. 7, 612-620.

379 Vrana, B., Mills, G.A., Dominiak, E., Greenwood, R., 2006. Calibration of the

380 Chemcatcher passive sampler for the monitoring of priority organic pollutants in 381 water. Environ. Pollut. 142, 333-343.

383 Vrana, B., Mills, G.A., Kotterman, M., Leonards, P., Booij, K., Greenwood, R., 2007. 384 Modelling and field application of the Chemcatcher passive sampler calibration data 385 for the monitoring of hydrophobic organic pollutants in water. Environ. Pollut. 145, 386 895-904. 